\title{
Projecting Antarctic ice discharge using response functions from SeaRISE ice-sheet models
}

\author{
A. Levermann ${ }^{1,2}$, R. Winkelmann ${ }^{1}$, S. Nowicki ${ }^{3}$, J. L. Fastook ${ }^{4}$, K. Frieler ${ }^{1}$, R. Greve ${ }^{5}$, H. H. Hellmer ${ }^{6}$, \\ M. A. Martin ${ }^{1}$, M. Meinshausen ${ }^{1,7}$, M. Mengel ${ }^{1}$, A. J. Payne ${ }^{8}$, D. Pollard ${ }^{9}$, T. Sato ${ }^{5}$, R. Timmermann ${ }^{6}$, \\ W. L. Wang ${ }^{3}$, and R. A. Bindschadler ${ }^{3}$ \\ ${ }^{1}$ Potsdam Institute for Climate Impact Research, Potsdam, Germany \\ ${ }^{2}$ Institute of Physics, Potsdam University, Potsdam, Germany \\ ${ }^{3}$ Code 615, Cryospheric Sciences Laboratory, NASA Goddard Space Flight Center, Greenbelt MD 20771 USA \\ ${ }^{4}$ Computer Science/Quaternary Institute, University of Maine, Orono, ME 04469, USA \\ ${ }^{5}$ Institute of Low Temperature Science, Hokkaido University, Sapporo 060-0819, Japan \\ ${ }^{6}$ Alfred Wegener Institute, Bremerhaven, Germany \\ ${ }^{7}$ School of Earth Sciences, The University of Melbourne, 3010 Melbourne, Australia \\ ${ }^{8}$ Bristol Glaciology Centre, University of Bristol, University Road, Clifton, Bristol BS8 1SS, UK \\ ${ }^{9}$ Earth and Environmental Systems Institute, Pennsylvania State University, University Park, PA 16802, USA
}

Correspondence to: A. Levermann (anders.levermann@pik-potsdam.de)

Received: 30 November 2013 - Published in Earth Syst. Dynam. Discuss.: 13 December 2013

Revised: 28 May 2014 - Accepted: 26 June 2014 - Published: 14 August 2014

\begin{abstract}
The largest uncertainty in projections of future sea-level change results from the potentially changing dynamical ice discharge from Antarctica. Basal ice-shelf melting induced by a warming ocean has been identified as a major cause for additional ice flow across the grounding line. Here we attempt to estimate the uncertainty range of future ice discharge from Antarctica by combining uncertainty in the climatic forcing, the oceanic response and the ice-sheet model response. The uncertainty in the global mean temperature increase is obtained from historically constrained emulations with the MAGICC-6.0 (Model for the Assessment of Greenhouse gas Induced Climate Change) model. The oceanic forcing is derived from scaling of the subsurface with the atmospheric warming from 19 comprehensive climate models of the Coupled Model Intercomparison Project (CMIP-5) and two ocean models from the EU-project Ice2Sea. The dynamic ice-sheet response is derived from linear response functions for basal ice-shelf melting for four different Antarctic drainage regions using experiments from the Sea-level Response to Ice Sheet Evolution (SeaRISE) intercomparison project with five different Antarctic ice-sheet models. The resulting uncertainty range for the historic Antarctic contribution to global sealevel rise from 1992 to 2011 agrees with the observed contribution for this period if we use the three ice-sheet models with an explicit representation of ice-shelf dynamics and account for the time-delayed warming of the oceanic subsurface compared to the surface air temperature. The median of the additional ice loss for the $21 \mathrm{st}$ century is computed to $0.07 \mathrm{~m}$ ( $66 \%$ range: $0.02-0.14 \mathrm{~m}$; $90 \%$ range: $0.0-0.23 \mathrm{~m})$ of global sea-level equivalent for the low-emission RCP-2.6 (Representative Concentration Pathway) scenario and $0.09 \mathrm{~m}$ (66\% range: $0.04-0.21 \mathrm{~m}$; $90 \%$ range: $0.01-0.37 \mathrm{~m}$ ) for the strongest RCP-8.5. Assuming no time delay between the atmospheric warming and the oceanic subsurface, these values increase to $0.09 \mathrm{~m}(66 \%$ range: $0.04-0.17 \mathrm{~m} ; 90 \%$ range: $0.02-0.25 \mathrm{~m}$ ) for RCP-2.6 and $0.15 \mathrm{~m}$ (66\% range: $0.07-0.28 \mathrm{~m} ; 90 \%$ range: $0.04-0.43 \mathrm{~m})$ for RCP-8.5. All probability distributions are highly skewed towards high values. The applied ice-sheet models are coarse resolution with limitations in the representation of grounding-line motion. Within the constraints of the applied methods, the uncertainty induced from different ice-sheet models is smaller than that induced by the external forcing to the ice sheets.
\end{abstract}




\section{Introduction}

The future evolution of global mean and regional sea level is important for coastal planning and associated adaptation measures (e.g. Hallegatte et al., 2013; Hinkel et al., 2014; Marzeion and Levermann, 2014). The Fourth Assessment Report (AR4) of the Intergovernmental Panel on Climate Change (IPCC) provided sea-level projections explicitly excluding changes in dynamic ice discharge, i.e. additional ice flow across the grounding line, from both Greenland and Antarctica (Alley et al., 2007). These contributions might however be significant for the next century, which would influence global mean (Van den Broeke et al., 2011) as well as regional sea-level changes (Mitrovica et al., 2009), especially since contribution from the ice sheets is clearly relevant on longer timescales (Levermann et al., 2013). While the part of the ice sheet directly susceptible to warming ocean waters on Greenland is limited, marine ice sheets in West Antarctica alone have the potential to elevate sea level globally by several metres (Bamber et al., 2009). Previous projections of the Antarctic ice-sheet mass balance have used fully coupled climate-ice-sheet models (e.g. Huybrechts et al., 2011; Vizcaíno et al., 2009). These simulations include feedbacks between the climate and the ice sheet and thereby provide very valuable information especially on a multi-centennial timescale. However, on shorter (i.e. decadal to centennial) timescales, the direct climatic forcing is likely to dominate the ice-sheet evolution compared to the feedbacks between ice dynamics and the surrounding climate. For 21st century projections it is thus appropriate to apply the output of comprehensive climate models as external forcing to the ice sheet, neglecting feedbacks while possibly improving on the accuracy of the forcing anomalies. Here we follow this approach.

In order to meet the relatively high standards that are set by climate models for the oceanic thermal expansion and glacier and ice-cap models which use the full range of state-of-theart climate projections, it is desirable to use a set of different ice-sheet models to increase the robustness of the projections of Antarctica's future sea-level contribution. While changes in basal lubrication and ice softening from surface warming and changes in surface elevation through altered precipitation can affect dynamic ice discharge from Antarctica, changes in basal melt underneath the ice shelves are here assumed to be the dominant driver of changes in dynamic ice loss.

Here we combine the dynamic response of five different Antarctic ice-sheet models to changes in basal iceshelf melt with the full uncertainty range of future climate change for each of the Representative Concentration Pathways (RCPs, Moss et al., 2010; Meinshausen et al., 2011b) using an ensemble of 600 projections with the climate emulator MAGICC-6.0 (Meinshausen et al., 2011a) which cover the range of projections of the current simulations from the
Coupled Model Intercomparison Projection, CMIP-5 (Taylor et al., 2012). To this end, we derive response functions for the five ice-sheet models from a standardized melting experiment (M2) from the Sea-level Response to Ice Sheet Evolution (SeaRISE) intercomparison project (Bindschadler et al., 2013). This community effort gathers a broad range of structurally different ice-sheet models to perform a climateforcing sensitivity study for both Antarctica (Nowicki et al., 2013a) and Greenland (Nowicki et al., 2013b). A suite of prescribed numerical experiments on a common set of input data represents different types of climate input, namely enhanced sub-shelf melting, enhanced sliding and surface temperature increase combined with enhanced net accumulation.

The spread in the response of the participating models to these experiments originates from differences in the stressbalance approximations, the treatment of grounding line motion, the implementation of ice-shelf dynamics, the computation of the surface-mass balance, and in the computational demand which sets strong limits on the spin-up procedure. Our approach allows us to identify the sensitivity of the response of coarse-resolution ice-sheet models to changes in different types of climate-related boundary conditions. An interpolation analysis of the results is performed (Bindschadler et al., 2013) in order to provide a best-guess estimate of the future sea-level contribution from the ice sheets.

Here we use linear response theory to project ice discharge for varying basal melt scenarios. The framework of linear response theory has been used before, for example to generalize climatic response to greenhouse gas emissions (Good et al., 2011). The probabilistic procedure for obtaining projections of the Antarctic dynamic discharge due to basal iceshelf melt and its uncertainty range is described in Sect. 4 and illustrated in Fig. 1. There are clear limitations to this approach which are discussed in the conclusions section at the end. In light of these limitations, which range from the use of linear response theory to missing physical process in the ice sheet but also in the oceanic models, the results presented here need to be considered as a first approach towards an estimate of Antarctica's future dynamic contribution to sea-level rise.

\section{Brief description of the ice-sheet and ocean models}

All ice-sheet models are described in detail by Bindschadler et al. (2013) (Table 2). Here we provide a brief summary referring to relevant publications from which more detailed descriptions can be obtained. All models applied are continental ice-sheet models and coarse in resolution. As a consequence, these models have deficiencies in the representation of the motion of the grounding line. This is documented in the Marine Ice Sheet Model Intercomparison Projects (MISMIP and MISMIP-3-D) (Pattyn et al., 2012, 


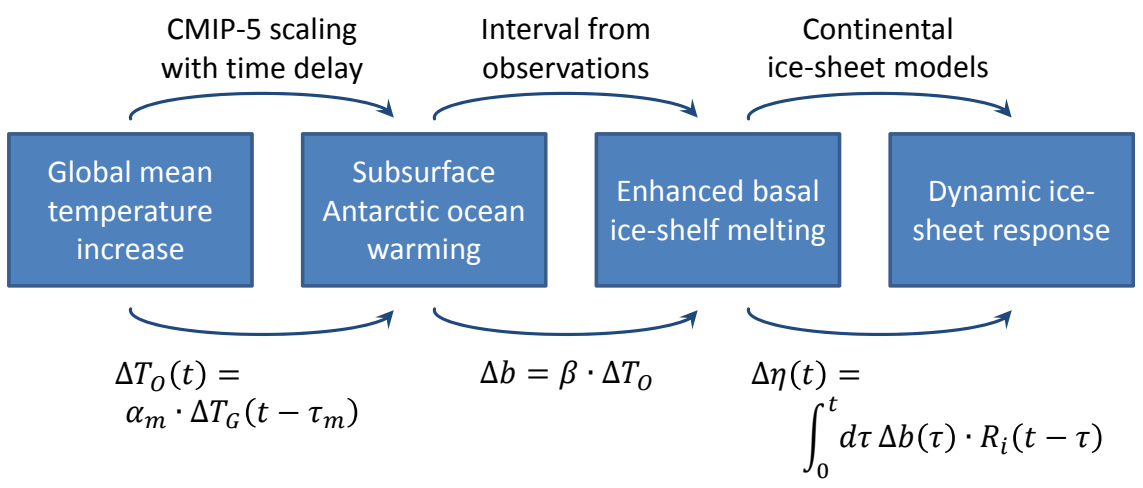

Figure 1. Schematic of procedure for the estimate of the uncertainty of the Antarctic dynamic contribution to future sea-level change. At each stage of the procedure, represented by the four boxes, a random selection is performed from a uniform distribution as indicated in the following. This procedure was carried out 50000 times for each RCP scenario to obtain the uncertainty ranges described throughout the study. First, one time evolution of the global mean temperature, $\Delta_{T_{\mathrm{G}}}$, was selected randomly out of an ensemble of 600 MAGICC-6.0 simulations. Second, 1 of 19 CMIP-5 climate models was selected randomly to obtain the scaling coefficient and time delay between the global mean temperature surface warming, $\Delta_{T_{\mathrm{G}}}$, and the subsurface oceanic warming, $\Delta_{T_{\mathrm{O}}}$. Third, a basal melt sensitivity, $\beta$, was selected randomly from the observed interval to translate the oceanic warming into additional basal ice-shelf melting. Finally, one of the ice-sheet models is selected randomly to use the corresponding response function, $R_{i}$, to obtain an ice discharge signal which is given in sea-level equivalent. The formulas describe the corresponding signal transformation at each step.

2013). Furthermore, the basal-melt sensitivity experiments which were used to derive the response function (as detailed in Sect. 3 were started from an equilibrium simulation and might thereby be biased towards a delayed response compared to the real Antarctic ice sheet which has evolved from a glacial period about 10000 years ago.

AIF: the Anisotropic Ice-Flow model is a 3-D ice-sheet model incorporating anisotropic ice flow and fully coupling dynamics and thermodynamics (Wang et al., 2012). It is a higher-order model with longitudinal and vertical shear stresses but currently without an explicit representation of ice shelves. The model uses the finite difference method to calculate ice-sheet geometry including isostatic bedrock adjustment, 3-D distributions of shear and longitudinal strain rates, enhancement factors which account for the effect of ice anisotropy, temperatures, horizontal and vertical velocities, shear and longitudinal stresses. The basal sliding is determined by Weertman's sliding law based on a cubic power relation of the basal shear stress. As the model lacks ice shelves, the prescribed melt rates are applied to the ice-sheet perimeter grid points whenever the bed is below sea level. The ice-sheet margin, which is equivalent to the grounding line in this model, moves freely within the model grid points and the grounding line is detected by hydrostatic equilibrium (i.e. the floating condition) without sub-grid interpolation.

PennState-3D: the Pennsylvania State University 3-D icesheet model uses a hybrid combination of the scaled shallow ice approximation (SIA) and shallow shelf approximation (SSA) equations for shearing and longitudinal stretching flow respectively. The location of the grounding line is determined by simple flotation, with sub-grid interpolation as in Gladstone et al. (2010). A parameterization re- lating ice velocity across the grounding line to local ice thickness is imposed as an internal boundary-layer condition, so that grounding-line migration is simulated reasonably well without the need for very high, i.e of the order of $100 \mathrm{~m}$, resolution (Schoof, 2007). Ocean melting below ice shelves and ice-shelf calving use simple parameterizations, along with a sub-grid parameterization at the floatingice edge (Pollard and Deconto, 2009; Pollard and DeConto, 2012). The PennState-3D model shows the best performance of grounding line motion within the MISMIP intercomparison compared to the other models applied here.

PISM: the Parallel Ice Sheet Model (www.pism-docs.org) used here is based on stable version 0.4, which incorporates the Potsdam Parallel Ice Sheet Model (PISM-PIK) (Winkelmann et al., 2011; Martin et al., 2011). Ice flow is approximated by a hybrid scheme incorporating both the SIA and SSA approximations (Bueler and Brown, 2009). An enthalpy formulation (Aschwanden et al., 2012) is used for thermodynamics, and the model employs a physical stressboundary condition to the "shelfy-stream" approximation at ice fronts, in combination with a sub-grid interpolation (Albrecht et al., 2011) and a kinematic first-order calving law (Levermann et al., 2012) at ice-shelf fronts. In PISM-PIK, the grounding line is not subject to any boundary conditions or flux corrections. Its position is determined from ice and bedrock topographies in each time step via the floatation criterion. The grounding line motion is thus influenced only indirectly by the velocities through the ice thickness evolution. Since the SSA (shallow shelf approximation) velocities are computed non-locally and simultaneously for the shelf and for the sheet, a continuous solution over the grounding line without singularities is ensured and buttressing effects are 
accounted for. The PISM model shows good performance of the grounding line motion within the MISMIP intercomparisons only at significantly higher resolution ( $1 \mathrm{~km}$ or finer) than applied here.

SICOPOLIS: the SImulation COde for POLythermal Ice Sheets is a three-dimensional, polythermal ice-sheet model that was originally created by Greve $(1995,1997)$ in a version for the Greenland ice sheet, and has been developed continuously since then (Sato and Greve, 2012) (www. sicopolis.net). It is based on finite-difference solutions of the shallow ice approximation for grounded ice (Hutter, 1983; Morland, 1984) and the shallow shelf approximation for floating ice (Morland, 1987; MacAyeal, 1989). Special attention is paid to basal temperate layers (that is, regions with a temperature at the pressure melting point), which are positioned by fulfilling a Stefan-type jump condition at the interface to the cold ice regions. Basal sliding is parameterized by a Weertman-type sliding law with sub-melt sliding (which allows for a gradual onset of sliding as the basal temperature approaches the pressure melting point (Greve, 2005)), and glacial isostasy is described by the elastic lithosphere/relaxing asthenosphere (ELRA) approach (Le Meur and Huybrechts, 1996). The position and evolution of the grounding line is determined by the floating condition. Between neighbouring grounded and floating grid points, the ice thickness is interpolated linearly, and the half-integer auxiliary grid point in between (on which the horizontal velocity is defined, Arakawa C grid) is considered as either grounded or floating depending on whether the interpolated thickness leads to a positive thickness above floatation or not. SICOPOLIS was not part of the MISMIP experiments (Pattyn et al., 2012). The performance of the ice-shelf solver was tested against the analytical solution for an ice-shelf ramp (Greve and Blatter, 2009, Sect. 6.4) and showed very good agreement of the horizontal velocity field already at low resolution, as discussed by Sato (2012). The grounding line motion of the model has however not been systematically tested yet.

UMISM: the University of Maine Ice Sheet Model consists of a time-dependent finite-element solution of the coupled mass, momentum and energy conservation equations using the SIA (Fastook, 1990, 1993; Fastook and Chapman, 1989; Fastook and Hughes, 1990; Fastook and Prentice, 1994) with a broad range of applications (for example, Fastook et al., 2012, 2011) The 3-D temperature field, on which the flow law ice hardness depends, is obtained from a 1-D finite-element solution of the energy conservation equation at each node without direct representation of horizontal heat advection. This thermodynamic calculation includes vertical diffusion and advection, but neglects horizontal movement of heat. Also included is internal heat generation produced by shear with depth and sliding at the bed. Boundary conditions consist of specified surface temperature and basal geothermal gradient. If the calculated basal temperature exceeds the pressure melting point, the basal boundary

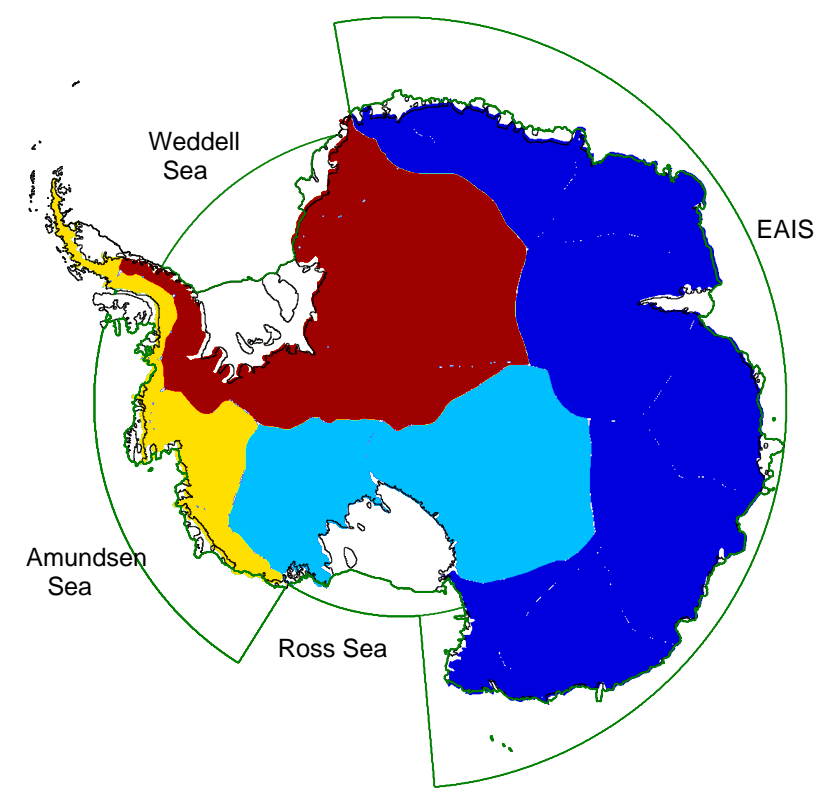

Figure 2. The four different basins for which ice-sheet response functions are derived from the SeaRISE M2 experiments. Green lines enclose the oceanic regions over which the subsurface oceanic temperatures were averaged. Vertical averaging was carried out over a $100 \mathrm{~m}$ depth range centred at the mean depth of the ice shelves in the region taken from Le Brocq et al. (2010) as provided in Table 1.

condition is changed to a specified temperature, and a basal melt rate is calculated from the amount of latent heat of fusion that must be absorbed to maintain this specified temperature. Conversely, if the basal temperature drops below the pressure melting point where water is already present at the bed, a similar treatment allows for the calculation of a rate of basal freezing. A map-plane solution for conservation of water at the bed, whose source is the basal melt or freeze-on rate provided by the temperature solution, allows for movement of the basal water down the hydrostatic pressure gradient (Johnson and Fastook, 2002). Areas of basal sliding can be specified if known, or determined internally by the model as regions where lubricating basal water is present, produced either by melting in the thermodynamic calculation or by movement of water beneath the ice sheet down the hydrostatic gradient. Ice shelves are not modelled explicitly in UMISM. However, a thinning rate at the grounding line produced by longitudinal stresses is calculated from a parameterization of the thinning of a floating slab (Weertman, 1957). No sub-grid grounding line interpolation is applied.

The oceanic forcing that is applied to the response functions as described in Sect. 4 is derived from a scaling of the oceanic subsurface temperature in four large-scale oceanic basins along the Antarctic coast (Fig. 2) with the global mean temperature increase under greenhouse-gas emission scenarios. To this end, 19 global climate models from the Coupled climate Model Intercomparison Project, Phase 5 (CMIP-5) 
were used. These models typically apply an oceanic resolution of several degrees both in latitude and longitude. This results in the fact that major climate variability processes such as the El Niño-Southern Oscillation (ENSO) phenomenon are not accurately represented. Important for the results discussed here is that these models are most likely not able to accurately represent the effects of mesoscale eddy motion. As shown, for example, by Hellmer et al. (2012) these might be crucial for abrupt warming events which may have significant impact on basal ice-shelf melt. This is a major limitation of the results presented here. The models used are likely missing any abrupt warming and are only able to capture large-scale warming signals.

Besides the probabilistic projections we apply the icesheet response functions to subsurface temperature projections from two different ocean models, namely the Bremerhaven Regional Ice Ocean Simulations (BRIOS) model and the Finite-Element Southern Ocean Model (FESOM).

BRIOS is a coupled ice-ocean model which resolves the Southern Ocean south of $50^{\circ} \mathrm{S}$ zonally at $1.5^{\circ}$ and meridionally at $1.5^{\circ} \times \cos \phi$. The water column is variably divided into 24 terrain-following layers. The sea-ice component is a dynamic-thermodynamic snow/ice model with heat budgets for the upper and lower surface layers (Parkinson and Washington, 1979) and a viscous-plastic rheology (Hibler, 1979). BRIOS considers the ocean-ice-shelf interaction underneath 10 Antarctic ice shelves (Beckmann et al., 1999; Hellmer, 2004) with time-invariant thicknesses, assuming flux divergence and mass balance to be in dynamical equilibrium. The model has been successfully validated by the comparison with mooring and buoy observations regarding, e.g. Weddell gyre transport (Beckmann et al., 1999), sea ice thickness distribution and drift in Weddell and Amundsen seas (Timmermann et al., 2002a; Assmann et al., 2005) and subice-shelf circulation (Timmermann et al., 2002b).

FESOM is a hydrostatic, primitive-equation ocean model with an unstructured grid that consists of triangles at the surface and tetrahedra in the ocean interior. It is based on the finite element model of the North Atlantic (Danilov et al., 2004, 2005) coupled to a dynamic-thermodynamic sea-ice model with a viscous-plastic rheology and evaluated in a global setup (Timmermann et al., 2009; Sidorenko et al., 2011). An ice-shelf component with a three-equation system for the computation of temperature and salinity in the boundary layer between ice and ocean and the melt rate at the ice-shelf base (Hellmer et al., 1998) has been implemented. Turbulent fluxes of heat and salt are computed with coefficients depending on the friction velocity following Holland and Jenkins (1999). The present setup uses a hybrid vertical coordinate and a global mesh with a horizontal resolution between 30 and $40 \mathrm{~km}$ in the offshore Southern Ocean, which is refined to $10 \mathrm{~km}$ along the Antarctic coast, $7 \mathrm{~km}$ under the larger ice shelves in the Ross and Weddell seas and to $4 \mathrm{~km}$ under the small ice shelves in the Amundsen Sea.
Table 1. Mean depth of ice shelves in the different regions denoted in Fig. 2 as computed from Le Brocq et al. (2010). Oceanic temperature anomalies were averaged vertically over a $100 \mathrm{~m}$ range around these depth.

\begin{tabular}{lc}
\hline Region & Depth [m] \\
\hline Amundsen Sea & 305 \\
Ross Sea & 312 \\
Weddell Sea & 420 \\
East Antarctica & 369 \\
\hline
\end{tabular}

Outside the Southern Ocean, resolution decreases to $50 \mathrm{~km}$ along the coasts and to about $250-300 \mathrm{~km}$ in the vast basins of the Atlantic and Pacific oceans, while on the other hand, some of the narrow straits that are important to the global thermohaline circulation (e.g. Fram and Denmark straits, and the region between Iceland and Scotland) are represented with high resolution (Timmermann et al., 2012). Ice-shelf draft, cavity geometry, and global ocean bathymetry have been derived from the RTopo- 1 data set (Timmermann et al., 2010) and thus consider data from many of the most recent surveys of the Antarctic continental shelf.

\section{Deriving the response functions}

In order to use the sensitivity experiments carried out within the SeaRISE project (Bindschadler et al., 2013), we assume that for the 21 st century the temporal evolution of the ice discharge can be expressed as

$$
S(t)=\int_{0}^{t} \mathrm{~d} \tau R(t-\tau) m(\tau),
$$

where $S$ is the sea-level contribution from ice discharge, $m$ is the forcing represented by the basal-melt rate and $R$ is the ice-sheet response function. $t$ is time starting from a period prior to the beginning of a significant forcing. The response function $R$ can thus be understood as the response to a deltapeak forcing with magnitude one.

$S_{\delta}(t)=\int_{0}^{t} \mathrm{~d} \tau R(t-\tau) \delta(\tau)=R(t)$

We express ice discharge throughout the paper in units of global mean sea-level equivalent. That means that in deriving the response functions we only diagnose ice loss above flotation that is relevant for sea level. As a simple consequence the response function is unitless. The basal ice-shelf melt signal as well as the ice-discharge signal used to derive the response functions are anomalies with respect to a baseline simulation under present-day boundary conditions (Bindschadler et al., 2013). 

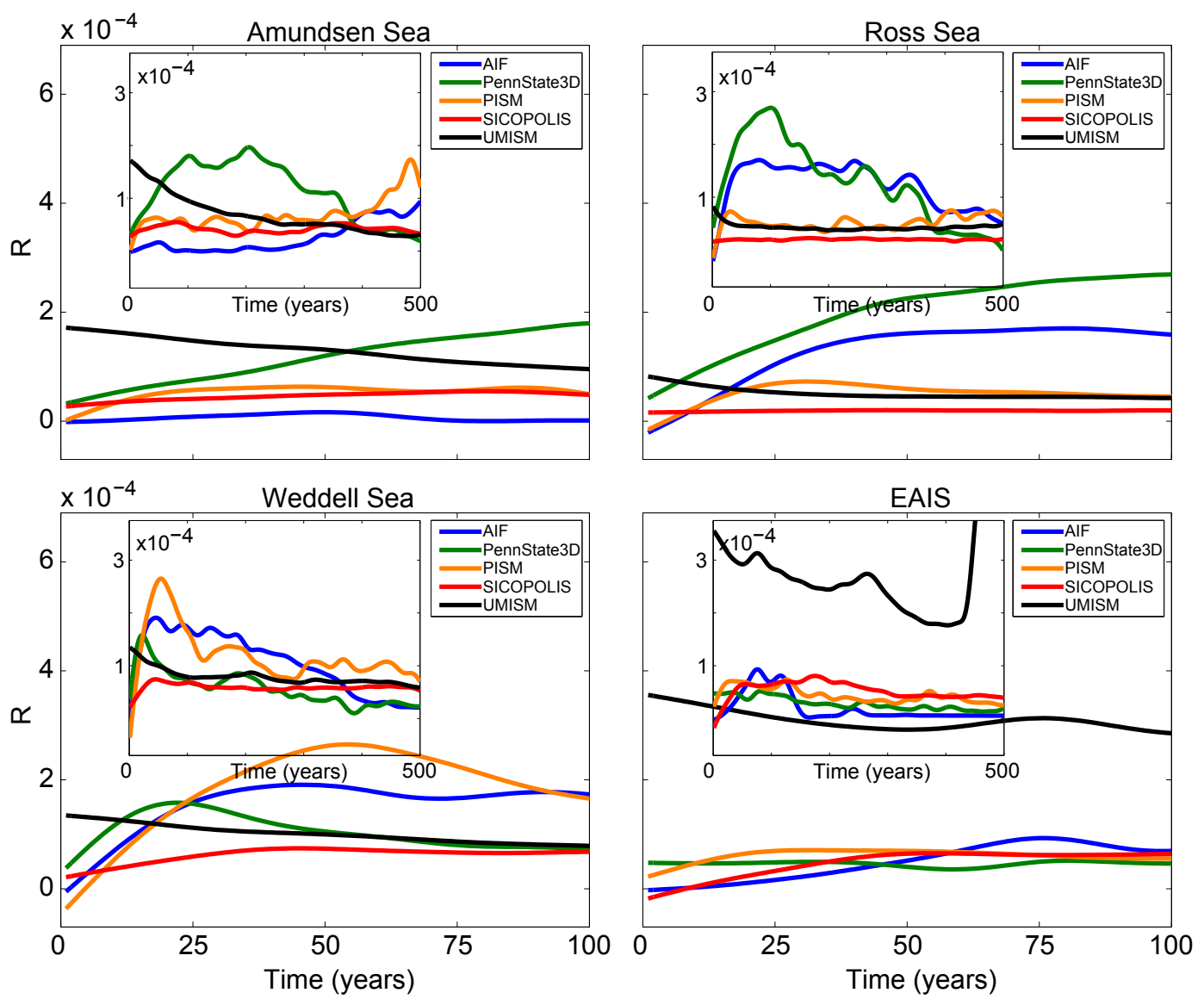

Figure 3. Linear response functions for the five ice-sheet models of Antarctica for each region as defined by Eq. (2) and as obtained from the SeaRISE-M2 experiments. The projections up to the year 2100 , as computed here, will be dominated by the response functions up to year 100 since this is the period of the dominant forcing. For completeness, the inlay shows the response function for the full 500 years, i.e the period of the original SeaRISE experiments. As can be seen from Eq. (1), the response function is dimensionless. While the response functions are different for each individual basin and model when derived from the weaker M1 experiment (Fig. 14), the uncertainty range for the sea-level contribution in 2100 is very similar, since it is dominated by the uncertainty in the climatic forcing (compare Fig. 11).

Linear response theory, as represented by Eq. (1), can only describe the response of a system up to a certain point in time; 100 years is a relatively short period for the response of an ice sheet and the assumption of a linear response is thereby justified. During this period of validity, Eq. (1) is also capable of capturing rather complex responses such as irregular oscillations (compare Fig. 3); the method is not restricted to monotonous behaviour. However, Eq. (1) implies that multiplying the forcing by any factor will change the response by the same factor. This can only be the case as long as there are no qualitative changes in the physical response of the system. Furthermore, any self-amplifying process such as the marine ice-sheet instability will not be captured accurately by Eq. (1) if the process dominates the response. Linear response theory can still be a valid approach in this case if the forcing dominates the response of the system. The weak forcing limitation is particularly relevant for the low emission scenario RCP-2.6. The forcing is likely to dominate the response for the relatively strong SeaRISE experiment M2 with additional homogeneous basal ice-shelf melting of $20 \mathrm{~m} \mathrm{a}^{-1}$ and for the strong warming scenario RCP-8.5 which is particularly relevant for an estimate of the full range of ice-discharge projections. In this study, we project only for 100 years with a time-delayed oceanic forcing of several decades (as detailed in Tables 2-5) for the full coast line of Antarctica. For this particular setup, the linear response approach will provide insights into the continental response of the ice sheet.

There are a number of ways to obtain the system-specific response function $R$ (e.g. Winkelmann and Levermann, 2013). Within the SeaRISE project, the switch-on basal-melt experiments can be used conveniently since their response directly provides the time integral of the response function for each individual ice-sheet model. Assuming that over a forcing period of 100 years the different topographic basins in Antarctica from which ice is discharged respond independently, we diagnose the additional ice flow from four basins separately (Fig. 2) and interpret them as the time integral of the response function for each separate basin. The response 


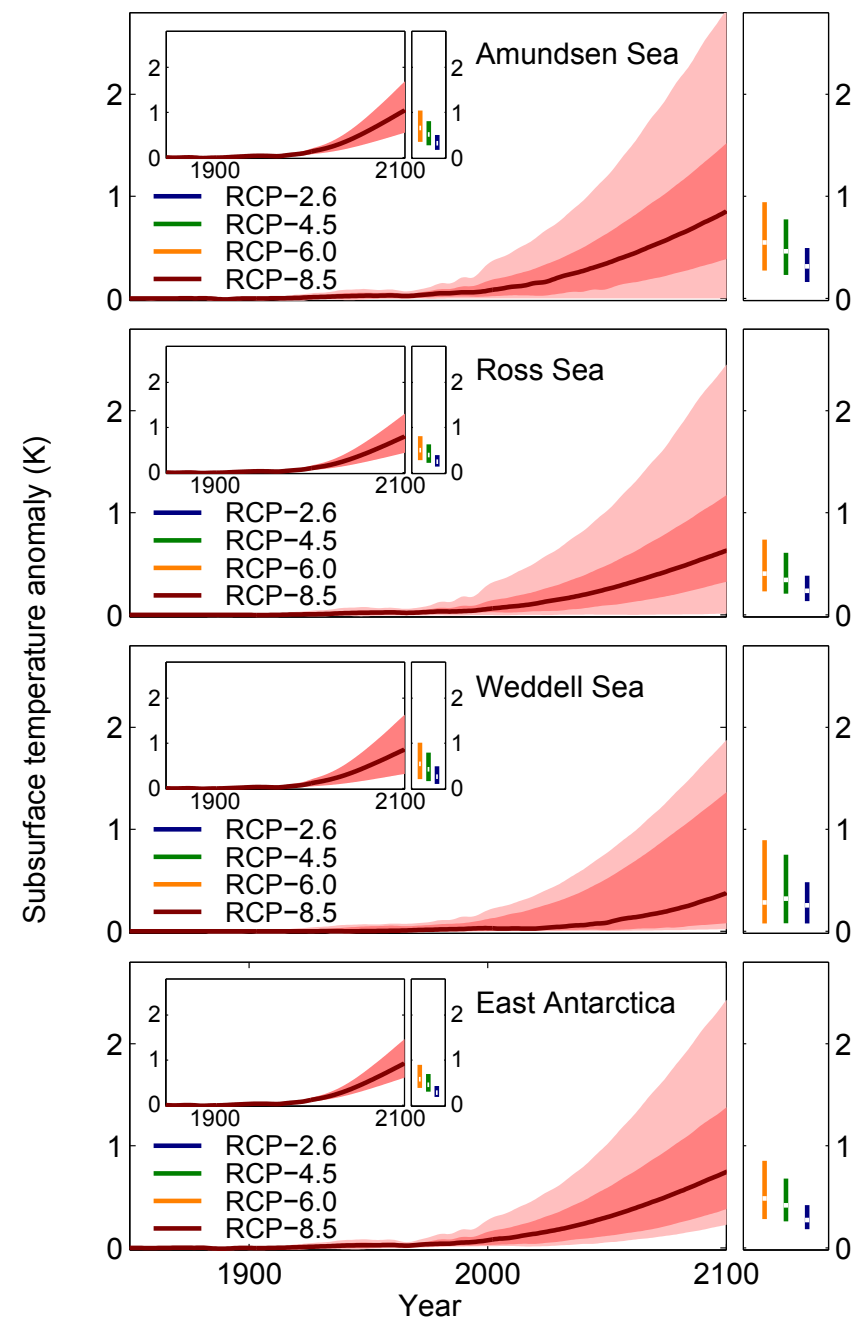

Figure 4. Oceanic subsurface-temperature anomalies outside the ice-shelf cavities as obtained from scaling the range of global mean temperature changes under the different RCP scenarios to the oceanic subsurface outside the ice-shelf cavities. For the downscaling, the oceanic temperatures were diagnosed off the shore of the ice-shelf cavities within the four regions defined in Fig. 2 at the depth of the mean ice-shelf thickness as defined in Table 1. These temperature anomalies were plotted against the global mean temperature increase for each of the 19 CMIP-5 climate models used here. The best scaling was obtained when using a time delay between global mean temperature and oceanic subsurface temperature anomalies. The scaling coefficients with the respective time delay are provided in Tables $2-5$. The thick red line corresponds to the median temperature evolution. The dark shading corresponds to the $66 \%$ percentile around the median (red). The light shading corresponds to the $90 \%$ percentile. Inlays show the temperature anomalies without time delay.
Table 2. Amundsen Sea sector: scaling coefficients and time delay $\Delta t$ between increases in global mean temperature and subsurface ocean temperature anomalies.

\begin{tabular}{lccccc}
\hline Model & $\begin{array}{c}\text { Coeff. } \\
\text { without } \Delta t\end{array}$ & $r^{2}$ & $\begin{array}{c}\Delta t \\
\text { [yr] }\end{array}$ & $\begin{array}{c}\text { Coeff. } \\
\text { with } \Delta t\end{array}$ & $r^{2}$ \\
\hline ACCESS1-0 & 0.17 & 0.86 & 0 & 0.17 & 0.86 \\
ACCESS1-3 & 0.30 & 0.94 & 0 & 0.30 & 0.94 \\
BNU-ESM & 0.37 & 0.88 & 30 & 0.56 & 0.92 \\
CanESM2 & 0.15 & 0.83 & 30 & 0.24 & 0.88 \\
CCSM4 & 0.22 & 0.89 & 0 & 0.22 & 0.89 \\
CESM1-BGC & 0.19 & 0.92 & 0 & 0.19 & 0.92 \\
CESM1-CAM5 & 0.12 & 0.92 & 0 & 0.12 & 0.92 \\
CSIRO-Mk3-6-0 & 0.16 & 0.79 & 30 & 0.28 & 0.83 \\
FGOALS-s2 & 0.24 & 0.90 & 55 & 0.54 & 0.93 \\
GFDL-CM3 & 0.26 & 0.81 & 35 & 0.49 & 0.85 \\
HadGEM2-ES & 0.23 & 0.70 & 0 & 0.23 & 0.70 \\
INMCM4 & 0.67 & 0.90 & 0 & 0.67 & 0.90 \\
IPSL-CM5A-MR & 0.07 & 0.22 & 90 & 0.44 & 0.45 \\
MIROC-ESM-CHEM & 0.12 & 0.74 & 5 & 0.13 & 0.75 \\
MIROC-ESM & 0.11 & 0.55 & 60 & 0.35 & 0.61 \\
MPI-ESM-LR & 0.27 & 0.80 & 5 & 0.29 & 0.82 \\
MRI-CGCM3 & 0.00 & 0.02 & 85 & -0.07 & 0.04 \\
NorESM1-M & 0.30 & 0.94 & 0 & 0.30 & 0.94 \\
NorESM1-ME & 0.31 & 0.89 & 0 & 0.31 & 0.89 \\
\hline
\end{tabular}

Table 3. Weddell Sea sector: scaling coefficients and time delay $\Delta t$ between increases in global mean temperature and subsurface ocean temperature anomalies.

\begin{tabular}{lccccc}
\hline Model & $\begin{array}{c}\text { Coeff. } \\
\text { without } \Delta t\end{array}$ & $r^{2}$ & $\begin{array}{c}\Delta t \\
\text { [yr] }\end{array}$ & $\begin{array}{c}\text { Coeff. } \\
\text { with } \Delta t\end{array}$ & $r^{2}$ \\
\hline ACCESS1-0 & 0.07 & 0.73 & 35 & 0.14 & 0.80 \\
ACCESS1-3 & 0.07 & 0.73 & 35 & 0.15 & 0.81 \\
BNU-ESM & 0.37 & 0.89 & 0 & 0.37 & 0.89 \\
CanESM2 & 0.11 & 0.82 & 55 & 0.31 & 0.91 \\
CCSM4 & 0.37 & 0.95 & 20 & 0.49 & 0.96 \\
CESM1-BGC & 0.37 & 0.95 & 25 & 0.53 & 0.96 \\
CESM1-CAM5 & 0.23 & 0.79 & 50 & 0.63 & 0.88 \\
CSIRO-Mk3-6-0 & 0.19 & 0.80 & 55 & 0.60 & 0.90 \\
FGOALS-s2 & 0.09 & 0.73 & 85 & 0.39 & 0.86 \\
GFDL-CM3 & 0.11 & 0.55 & 60 & 0.31 & 0.62 \\
HadGEM2-ES & 0.31 & 0.92 & 0 & 0.31 & 0.92 \\
INMCM4 & 0.26 & 0.83 & 10 & 0.30 & 0.83 \\
IPSL-CM5A-MR & -0.02 & 0.00 & 85 & -0.06 & 0.03 \\
MIROC-ESM-CHEM & 0.07 & 0.50 & 65 & 0.32 & 0.77 \\
MIROC-ESM & 0.03 & 0.27 & 65 & 0.18 & 0.59 \\
MPI-ESM-LR & 0.08 & 0.65 & 85 & 0.41 & 0.70 \\
MRI-CGCM3 & 0.21 & 0.63 & 40 & 0.47 & 0.83 \\
NorESM1-M & 0.26 & 0.90 & 5 & 0.28 & 0.92 \\
NorESM1-ME & 0.25 & 0.85 & 50 & 0.64 & 0.92 \\
\hline
\end{tabular}

function for each basin is shown in Fig. 3. The aim of this study is specifically to capture differences between individual ice-sheet models, which are nicely illustrated by their different response functions. To obtain $R$ we use the response to the temporal stepwise increase in basal melt by $20 \mathrm{~m} \mathrm{a}^{-1}$ (denoted M2 experiment in Bindschadler et al., 2013). The icesheet response to a step forcing is equivalent to the temporal 
Table 4. Ross Sea sector: scaling coefficients and time delay $\Delta t$ between increases in global mean temperature and subsurface ocean temperature anomalies.

\begin{tabular}{lccccc}
\hline Model & $\begin{array}{c}\text { Coeff. } \\
\text { without } \Delta t\end{array}$ & $r^{2}$ & $\begin{array}{c}\Delta t \\
\text { [yr] }\end{array}$ & $\begin{array}{c}\text { Coeff. } \\
\text { with } \Delta t\end{array}$ & $r^{2}$ \\
\hline ACCESS1-0 & 0.18 & 0.77 & 20 & 0.26 & 0.79 \\
ACCESS1-3 & 0.09 & 0.76 & 15 & 0.12 & 0.77 \\
BNU-ESM & 0.28 & 0.83 & 20 & 0.36 & 0.84 \\
CanESM2 & 0.14 & 0.74 & 45 & 0.32 & 0.80 \\
CCSM4 & 0.14 & 0.91 & 5 & 0.15 & 0.92 \\
CESM1-BGC & 0.14 & 0.90 & 0 & 0.14 & 0.90 \\
CESM1-CAM5 & 0.16 & 0.85 & 0 & 0.16 & 0.85 \\
CSIRO-Mk3-6-0 & -0.06 & 0.28 & 0 & -0.06 & 0.28 \\
FGOALS-s2 & 0.18 & 0.89 & 60 & 0.45 & 0.93 \\
GFDL-CM3 & 0.23 & 0.85 & 25 & 0.37 & 0.89 \\
HadGEM2-ES & 0.25 & 0.62 & 0 & 0.25 & 0.62 \\
INMCM4 & 0.59 & 0.83 & 0 & 0.59 & 0.83 \\
IPSL-CM5A-MR & 0.02 & 0.04 & 95 & 0.14 & 0.12 \\
MIROC-ESM-CHEM & 0.23 & 0.85 & 0 & 0.23 & 0.85 \\
MIROC-ESM & 0.23 & 0.78 & 0 & 0.23 & 0.78 \\
MPI-ESM-LR & 0.16 & 0.70 & 40 & 0.31 & 0.73 \\
MRI-CGCM3 & 0.08 & 0.04 & 0 & 0.08 & 0.04 \\
NorESM1-M & 0.12 & 0.79 & 0 & 0.12 & 0.79 \\
NorESM1-ME & 0.12 & 0.68 & 20 & 0.16 & 0.73 \\
\hline
\end{tabular}

Table 5. East Antarctic Sea sector: scaling coefficients and time delay $\Delta t$ between increases in global mean temperature and subsurface ocean temperature anomalies.

\begin{tabular}{lccccc}
\hline Model & $\begin{array}{c}\text { Coeff. } \\
\text { without } \Delta t\end{array}$ & $r^{2}$ & $\begin{array}{c}\Delta t \\
\text { [yr] }\end{array}$ & $\begin{array}{c}\text { Coeff. } \\
\text { with } \Delta t\end{array}$ & $r^{2}$ \\
\hline ACCESS1-0 & 0.20 & 0.92 & 30 & 0.35 & 0.94 \\
ACCESS1-3 & 0.27 & 0.92 & 0 & 0.27 & 0.92 \\
BNU-ESM & 0.35 & 0.92 & 0 & 0.35 & 0.92 \\
CanESM2 & 0.21 & 0.96 & 0 & 0.21 & 0.96 \\
CCSM4 & 0.13 & 0.96 & 5 & 0.13 & 0.97 \\
CESM1-BGC & 0.12 & 0.94 & 25 & 0.17 & 0.95 \\
CESM1-CAM5 & 0.15 & 0.94 & 0 & 0.15 & 0.94 \\
CSIRO-Mk3-6-0 & 0.22 & 0.93 & 15 & 0.28 & 0.94 \\
FGOALS-s2 & 0.17 & 0.90 & 55 & 0.41 & 0.94 \\
GFDL-CM3 & 0.21 & 0.89 & 35 & 0.39 & 0.93 \\
HadGEM2-ES & 0.23 & 0.95 & 0 & 0.23 & 0.95 \\
INMCM4 & 0.55 & 0.97 & 0 & 0.55 & 0.97 \\
IPSL-CM5A-MR & 0.14 & 0.89 & 0 & 0.14 & 0.89 \\
MIROC-ESM-CHEM & 0.11 & 0.89 & 0 & 0.11 & 0.89 \\
MIROC-ESM & 0.09 & 0.85 & 50 & 0.24 & 0.88 \\
MPI-ESM-LR & 0.20 & 0.94 & 15 & 0.26 & 0.95 \\
MRI-CGCM3 & 0.26 & 0.94 & 0 & 0.26 & 0.94 \\
NorESM1-M & 0.15 & 0.76 & 0 & 0.15 & 0.76 \\
NorESM1-ME & 0.15 & 0.74 & 60 & 0.49 & 0.85 \\
\hline
\end{tabular}

integral of the response function $R$ with $t=0$ being the time of the switch-on in forcing:

$S_{\mathrm{sf}}(t)=\int_{0}^{t} \mathrm{~d} \tau R(t-\tau) \Delta m_{0} \cdot \Theta(\tau)=\Delta m_{0} \cdot \int_{0}^{t} \mathrm{~d} \tau R(\tau)$,

where $\Theta(\tau)$ is the Heaviside function which is zero for negative $\tau$ and one otherwise. We thus obtain the response func-
Table 6. Projections of ice discharge in 2100 according to Fig. 12. Numbers are in metres sea-level equivalent for the different global climate RCP scenarios with and without time delay $\Delta t$. The models PennState-3D, PISM and SICOPOLIS have an explicit representation of ice-shelf dynamics and are denoted "shelf models".

\begin{tabular}{lcccccc}
\hline Setup & RCP & Median & $17 \%$ & $83 \%$ & $5 \%$ & $95 \%$ \\
\hline Shelf models & 2.6 & 0.07 & 0.02 & 0.14 & 0.0 & 0.23 \\
with $\Delta t$ & 4.5 & 0.07 & 0.03 & 0.16 & 0.01 & 0.27 \\
& 6.0 & 0.07 & 0.03 & 0.17 & 0.01 & 0.28 \\
& 8.5 & 0.09 & 0.04 & 0.21 & 0.01 & 0.37 \\
\hline Shelf models & 2.6 & 0.09 & 0.04 & 0.17 & 0.02 & 0.25 \\
without $\Delta t$ & 4.5 & 0.11 & 0.05 & 0.20 & 0.02 & 0.30 \\
& 6.0 & 0.11 & 0.05 & 0.21 & 0.02 & 0.31 \\
& 8.5 & 0.15 & 0.07 & 0.28 & 0.04 & 0.43 \\
\hline All models & 2.6 & 0.08 & 0.03 & 0.17 & 0.01 & 0.27 \\
with $\Delta t$ & 4.5 & 0.09 & 0.03 & 0.20 & 0.01 & 0.33 \\
& 6.0 & 0.09 & 0.03 & 0.20 & 0.01 & 0.34 \\
& 8.5 & 0.11 & 0.04 & 0.27 & 0.01 & 0.47 \\
\hline All models & 2.6 & 0.11 & 0.05 & 0.19 & 0.02 & 0.29 \\
without $\Delta t$ & 4.5 & 0.13 & 0.06 & 0.24 & 0.03 & 0.36 \\
& 6.0 & 0.13 & 0.06 & 0.25 & 0.03 & 0.38 \\
& 8.5 & 0.18 & 0.08 & 0.34 & 0.04 & 0.54 \\
\hline
\end{tabular}

tion from

$R(t)=\frac{1}{\Delta m_{0}} \cdot \frac{\mathrm{d} S_{\mathrm{sf}}}{\mathrm{d} t}(t)$

For the main results of this study we use the M2 experiment. While $20 \mathrm{~m} \mathrm{a}^{-1}$ is a strong additional melting, it is within the range of potential future sub-shelf melt rates as determined from the projected subsurface warming (see Fig. 4) and the empirical basal melt coefficients $\left(7-16 \mathrm{~m} \mathrm{a}^{-1} \mathrm{~K}^{-1}\right.$, Sect. 4.3). It provides a good signal-to-noise ratio in the experiments, i.e. the response of the ice sheet to the forcing is dominated by the forcing and not by internal oscillations or long-term numerical drift. Since a linear relation between response and forcing is assumed (Eq. 1), the forcing from which the response functions are derived should be similar to the forcing applied in the projections. Basal ice-shelf melt rates of the M1 $\left(2 \mathrm{ma}^{-1}\right)$ and M3 $\left(200 \mathrm{~m} \mathrm{a}^{-1}\right)$ experiments are either too low or too high and consequently yield slightly different results. Please note, however, that the explicit choice of the response function is of second-order importance with respect to the uncertainty range of the sea-level projection. This can be seen when applying the response functions as obtained from the M1 experiments (see the Appendix). While the model- and basin-specific response functions may differ, the uncertainty range of the sea-level projections until 2100 is very similar to the range obtained from the M2 experiment. The reason for this similarity of the ranges is that most of the uncertainty arises from the uncertainty in the external forcing, while the response functions provide merely the magnitude of the continental-scale response. See the Appendix for more details. 


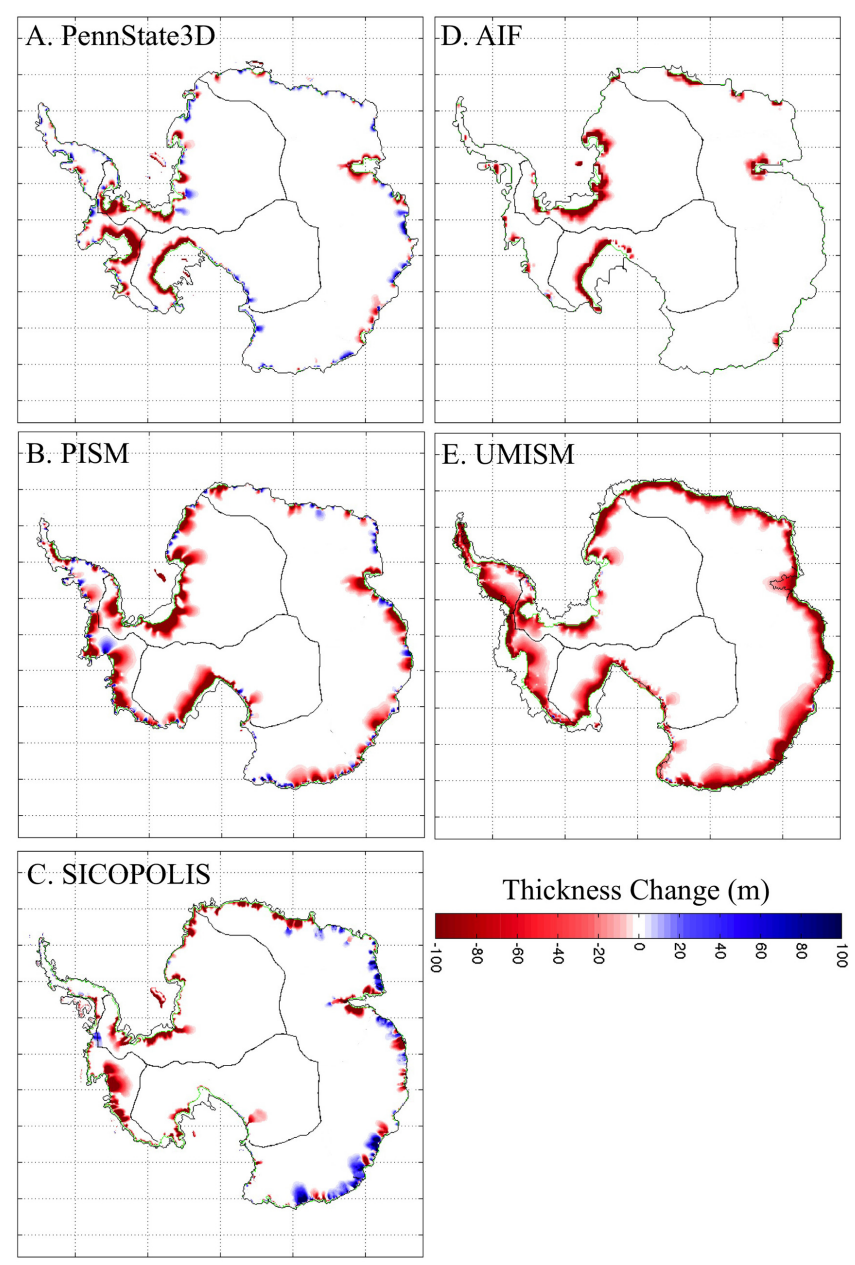

Figure 5. Ice-thickness change after 100 years under the SeaRISE experiment with homogeneous increase in basal ice-shelf melting of $20 \mathrm{~m} \mathrm{a}^{-1}$ (experiment M2 and Fig. 8 in Nowicki et al., 2013a). Due to their coarse resolution, some models with explicit representation of ice shelves such as the PISM model tend to underestimate the length of the coastline to which an ice shelf is attached which might lead to an underestimation of the ice loss. The UMISM model assumes basal melting along the entire coastline which is likely to result in an overestimation of the effect. Black contours represent the initial grounding line which moved to the green contour during the M2 experiment after 100 years. Lines within the continent show the drainage basins as in Fig. 2

The spatial distribution of the ice loss after 100 years through additional basal ice-shelf melting illustrates the different dynamics of the ice-sheet models resulting from, for example, different representations of ice dynamics, surface mass balance, basal sliding parameterizations and numerical implementation (Fig. 5). Part of the individual responses result from the different representations of the basal ice-shelf melt. In the UMISM model, basal melt was applied along the entire coastline which yields a particularly strong response in East Antarctica (Fig. 3). This is likely an overestimation of ice loss compared to models with an explicit representation of ice shelves. On the other hand, coarse-resolution ice-sheet models as used here cannot capture small ice shelves as they are present especially around East Antarctica. These models thus have a tendency to underestimate the fraction of the coastal ice that is afloat and thus the sensitivity to changes in ocean temperature might be also underestimated (compare, for example, Martin et al. (2011) for the PISM model). While we will also provide projections using all five models, the main focus of the study is on the three models with explicit representation of ice shelves (PennState-3D, PISM and SICOPOLIS).

\section{Probabilistic approach}

We aim to estimate the sea-level contribution from Antarctic dynamic ice discharge induced by basal ice-shelf melting driven by the global mean temperature evolution. In order to capture the climate uncertainty as well as the uncertainty in the oceanic response and the ice-sheet response, we follow a probabilistic approach that comprises four steps.

The schematic in Fig. 1 illustrates the procedure. At each of the four stages, represented by the four boxes, a random selection is performed from a uniform distribution as indicated in the following. The equations for each step are provided in Fig. 1.

a. For each scenario, a climate forcing, i.e. global mean temperature evolution, that is consistent with the observed climate change and the range of climate sensitivity of $2-4.5^{\circ} \mathrm{C}$ for a doubling of $\mathrm{CO}_{2}$ is randomly and uniformly selected from an ensemble of 600 MAGICC6.0 simulations. This selection yields a global mean temperature time series, $\Delta_{T_{\mathrm{G}}}$, from the year 1850 to the year 2100 .

b. Second, 1 of 19 CMIP- 5 climate models is selected randomly to obtain the scaling coefficient and time delay between the global mean temperature surface warming, $\Delta_{T_{\mathrm{G}}}$, and the subsurface oceanic warming, $\Delta_{T_{\mathrm{O}}}$. The global mean temperature evolution from step (a) is translated into a time series of subsurface ocean temperature change by use of the corresponding scaling coefficients and the associated time delay.

c. Third, a basal melt sensitivity, $\beta$, is selected randomly from the observed interval, to translate the oceanic warming into additional basal ice-shelf melting. The coefficient to translate the subsurface ocean temperature evolution into a sub-shelf melt rate is randomly drawn from the observation-based interval $7 \mathrm{~m} \mathrm{a}^{-1} \mathrm{~K}^{-1}$ (Jenkins, 1991) to $16 \mathrm{~m} \mathrm{a}^{-1} \mathrm{~K}^{-1}$ (Payne et al., 2007).

d. To translate the melt rate into sea-level-relevant ice loss from the associated ice-sheet basin, we randomly pick one response function as derived in Sect. 3 (Fig. 3) and 
combine them with random selections of the forcing obtained from steps (a)-(c).

The procedure is repeated 50000 times for each RCP scenario.

\subsection{Global mean temperature evolution}

We here use the Representative Concentration Pathways (RCPs) (Moss et al., 2010; Meinshausen et al., 2011b). The range of possible changes in global mean temperature that result from each RCP is obtained by constraining the response of the emulator model MAGICC 6.0 (Meinshausen et al., 2011a) with the observed temperature record. This procedure has been used in several studies and aims to cover the possible global climate response to specific greenhouse-gas emission pathways (e.g. Meinshausen et al., 2009). Here we use a set of 600 time series of global mean temperature from the year 1850 to 2100 for each RCP that cover the full range of future global temperature changes as detailed in Schewe et al. (2011).

\subsection{Subsurface oceanic temperatures from CMIP-5}

We use the simulations of the recent Coupled Model Intercomparison Project (CMIP-5) and obtain a scaling relationship between the anomalies of the global mean temperature and the anomalies of the oceanic subsurface temperature for each model. This has been carried out for the CMIP-3 experiments by Winkelmann et al. (2012) and is repeated here for the more recent climate models of CMIP-5.

Our scaling approach is based on the assumption that anomalies of the ocean temperatures resulting from global warming scale with the respective anomalies in global mean temperature. This approach may not be valid for absolute values. The assumption is consistent with the linear-response assumption underlying Eq. (1). We use oceanic temperatures from the subsurface at the mean depth of the ice-shelf underside in each sector (Table 1) to capture the conditions at the entrance of the ice-shelf cavities.

The surface warming signal needs to be transported to depth; therefore, the best linear regression is found with a time delay between global mean surface air temperature and subsurface oceanic temperatures. Results are detailed in Sect. 6.1. For the probabilistic projections, the scaling coefficients are randomly drawn from the provided sets.

\subsection{Empirical basal melt coefficients}

We apply an empirical relation to transform ocean temperature anomalies to basal ice-shelf melt anomalies. Observations suggest an interval of $7 \mathrm{~m} \mathrm{a}^{-1} \mathrm{~K}^{-1}$ (Jenkins, 1991) to $16 \mathrm{~m} \mathrm{a}^{-1} \mathrm{~K}^{-1}$ (Payne et al., 2007). See Holland et al. (2008) for a detailed discussion and comparison to other observations. The coefficient used for each projection is drawn randomly and uniformly from this interval. For comparison, if the temperature change were to be transported undiluted into the cavity and through the turbulent mixed layer underneath the ice shelf, the simple formula

$m=\frac{\rho_{\mathrm{O}} c_{p_{\mathrm{O}}} \gamma_{T}}{\rho_{\mathrm{i}} L_{\mathrm{i}}} \cdot \delta T_{\mathrm{O}} \approx 42 \frac{m}{a K} \cdot \delta T_{\mathrm{O}}$

would lead to a much higher melt rate, where $\rho_{\mathrm{O}}=$ $1028 \mathrm{~kg} \mathrm{~m}^{-3}$ and $c_{p_{\mathrm{O}}}=3974 \mathrm{~J} \mathrm{~kg}^{-1} \mathrm{~K}^{-1}$ are the density and heat capacity of ocean water. $\rho_{\mathrm{i}}=910 \mathrm{~kg} \mathrm{~m}^{-3}$ and $L_{\mathrm{i}}=$ $3.35 \times 10^{5} \mathrm{~J} \mathrm{~kg}^{-1}$ are ice density and latent heat of ice melt and $\gamma_{T}=10^{-4}$ as adopted from Hellmer and Olbers (1989).

\subsection{Translating melt rates into sea-level-relevant ice loss}

The response functions as derived in Sect. 3 allow translating the melting anomalies into changes in dynamic ice discharge from the Antarctic ice sheet. By randomly selecting a response function from the derived set, we cover the uncertainty from the different model responses. The main analysis is based on the response functions from the ice-sheet models with explicit ice-shelf representation. This choice was made because the application of the basal ice-shelf melting signal was less well defined for the models without explicit representation of the ice shelves. As a consequence the melting in these models was applied directly at the coast of the ice sheet in the first grounded grid cell. The area of melting was selected as the entire coast line in the case of the UMISM model and along the current shelf regions in the AIF model. These models were thus not included in the general uncertainty analysis.

\section{Application of ice-sheet response functions to projections from regional ocean models}

We first illustrate the direct application of the response function outside the probabilistic framework. We use melt rate projections from the high-resolution global finite-element FESOM and the regional ocean model BRIOS to derive the dynamic ice loss from the Weddell and Ross sea sectors.

Regional climate-change scenarios available from simulations for these models have been presented by Hellmer et al. (2012) and Timmermann and Hellmer (2013). We utilize data from the SRES A1B scenario, which represents greenhouse gas forcing between the RCP-6.0 and RCP-8.5 and the E1 scenario of the IPCC-AR4 (Alley et al., 2007), which is comparable to RCP-2.6. Both models were forced with boundary conditions obtained from two global climate models under these scenarios: ECHAM (European Centre/Hamburg Model)-5 (full lines in Fig. 6) and HadCM (Hadley Centre Coupled Model)-3 (dashed lines in Fig. 6). Note that temperatures decline in the Ross sector for HadCM-3 simulations and the Weddell sea for ECHAM-5 driven FESOM simulations which leads to negative melt rates. Since such declining melt rates or even refreezing corresponds to a different physical process, it is unlikely that the linear response 

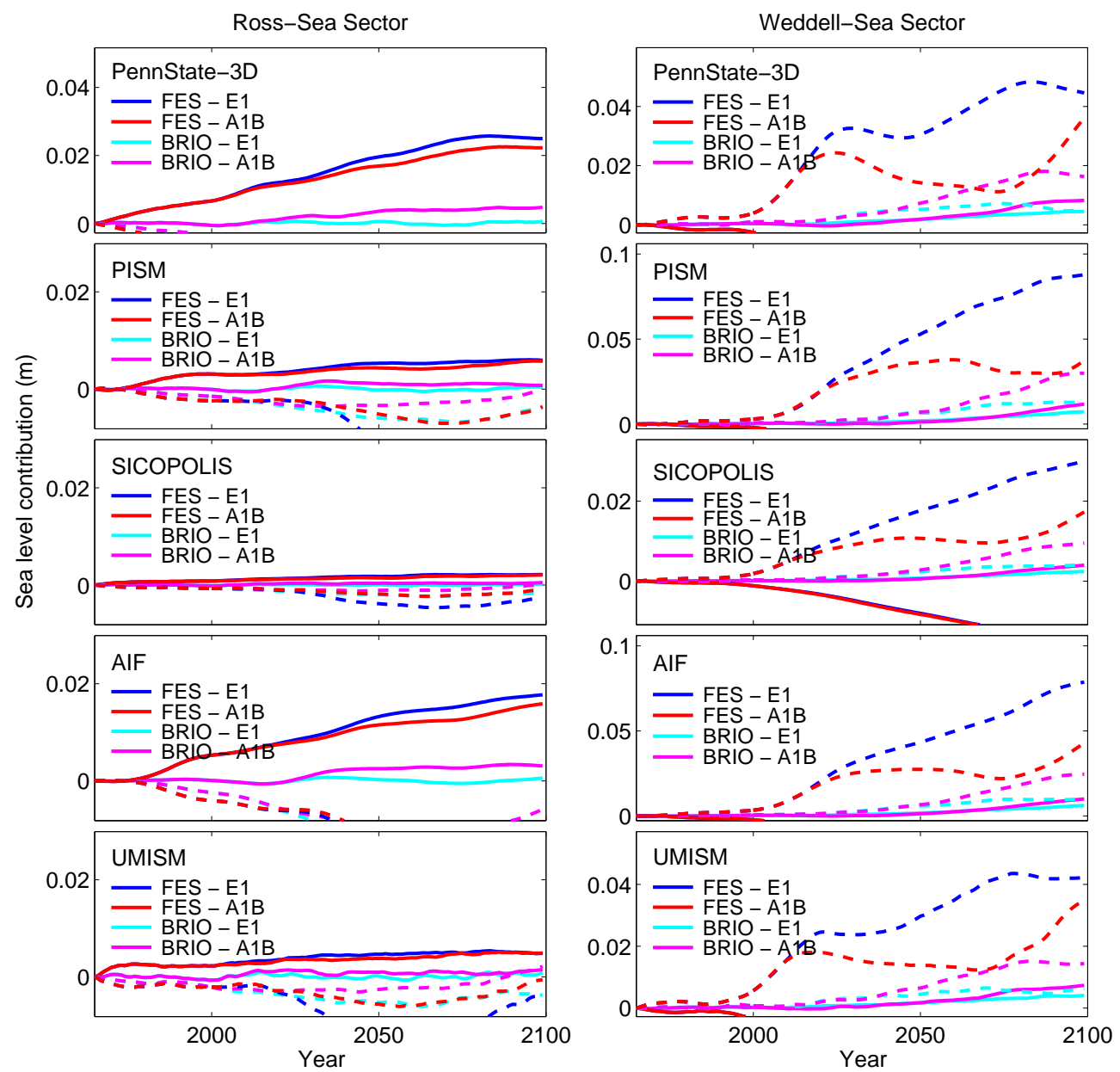

Figure 6. Ice loss as obtained from forcing the five response functions (Fig. 3) with the basal melt rates from the high-resolution global finite-element model FESOM (FES) and the regional ocean model BRIOS (BRIO). The full lines represent simulations in which BRIOS and FESOM were forced with the global climate model ECHAM-5; dashed lines correspond to a forcing with the HadCM-3 global climate model. Results are shown for the strong climate-change scenario A1B and the relatively low-emission scenario E1. A medium basal melt sensitivity of $11.5 \mathrm{~m} \mathrm{a}^{-1} \mathrm{~K}^{-1}$ was applied. The results illustrate the important role of the global climatic forcing.

functions from the SeaRISE experiments are applicable in such a case.

Though ocean model and scenario uncertainty are present, Fig. 6 shows that the role of the global climate model in projecting ice discharge is the dominating uncertainty as has already been discussed by Timmermann and Hellmer (2013). It therefore encourages the use of the broadest possible spectrum of climatic forcing in order to cover the high uncertainty from the choice of the global climate model.

\section{Probabilistic projections of the Antarctic sea level contribution}

\subsection{Scaling coefficients for subsurface ocean temperatures}

The scaling coefficients and the time delay determined from the 19 CMIP-5 coupled climate models are detailed in Tables 2-5. The high $r^{2}$ values support the validity of the linear regression except for the IPSL model where also the slope between the two temperature signals is very low. We explicitly keep this model in order to include the possibility that almost no warming occurs underneath the ice shelves.

Figure 4 shows the median and the 66 and $90 \%$ probability ranges for the oceanic subsurface temperatures, denoted the likely and very likely range by the IPCC-AR5 (IPCC, 2013), as obtained from a random selection of global mean temperature pathways combined with a randomly selected 

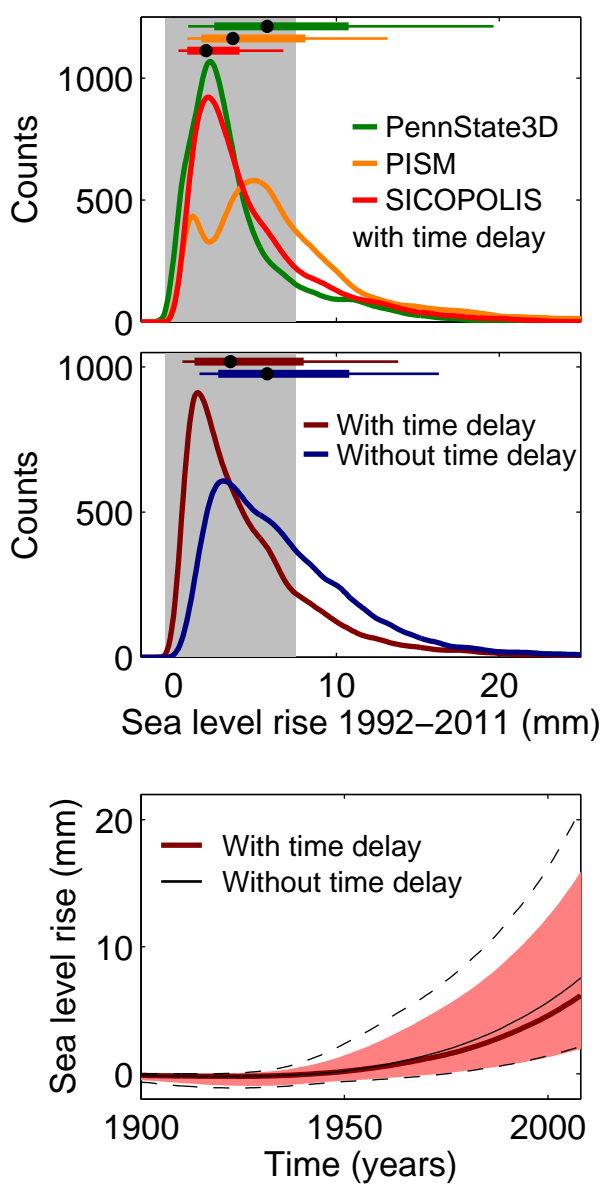

Figure 7. Uncertainty range including climate, ocean and ice-sheet uncertainty for the projected change of the observational period 1992-2011. Upper panel: probability distribution for the three models with explicit representation of ice shelves (PennState-3D, PISM, SICOPOLIS). Middle panel: probability distribution with time delay (dark red) and without (dark blue) for three the models with explicit ice-shelf representation (shelf models). The grey shading in the upper two panels provides the estimated range from observations following Shepherd et al. (2012). The likely range obtained with time delay is almost identical to the observed range. All distributions are highly skewed towards high sea-level contributions which strongly influences the median (black dot at the top of the panel), the $66 \%$ range (thick horizontal line) and the $90 \%$ range (thin horizontal line). Lower panel: time evolution for the hindcast projection using only the shelf models: with time delay, one obtains the red line as the median time series; the red shading provides the likely or $66 \%$ range. The black line shows the median without time delay together with the likely range for this case as dashed lines.

scaling coefficient and the associated time delay $\Delta t$ from Tables 2-5. Though physical reasons for a time delay between the surface and the subsurface temperatures exist, we find a high correlation also without applying a time delay. As the oceanic response of the coarse-resolution climate models applied here is likely to underestimate some small-scale transport processes (i.e. Hellmer et al., 2012), it is useful to also

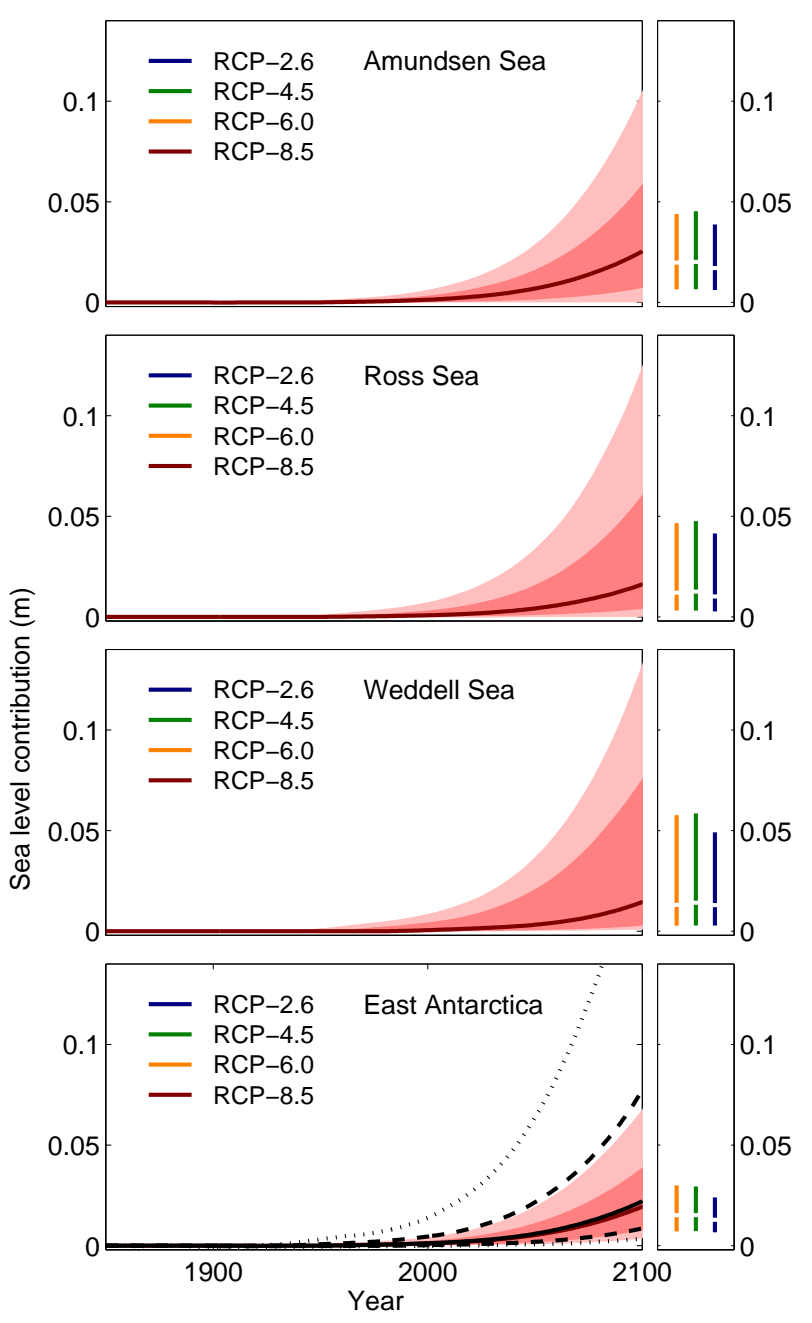

Figure 8. Uncertainty range of contributions to global sea level from basal-melt induced ice discharge from Antarctica for the different basins. Results shown here include the three ice-sheet models with explicit representation of ice-shelf dynamics and the global climate forcing applied with a time delay as given in Tables 2-5. The full red curve is the median enclosed by the dark shaded $66 \%$ range and the light shaded $90 \%$ range of the distribution for the RCP-8.5 scenario. Coloured bars at the right show the other scenarios' $66 \%$ range intersected by the median. The full distribution is given in Fig. 9. The strongest difference between models with and without explicit representation of ice shelves occurs in East Antarctica as exemplified in the lower panel. The dashed black line envelopes the $66 \%$ range of all models, the full black line is the median and the dotted line the $90 \%$ percentile.

provide results without time delay to bracket the full range of response. The oceanic temperature time series without time delay are provided as inlays in Fig. 4.

For comparison, Yin et al. (2011) assessed output from 19 atmosphere-ocean general circulation models (AOGCMs) under scenario A1B to determine how subsurface temperatures are projected to evolve around the ice sheets. They show decadal-mean warming of $0.4-0.7$ and $0.4-0.9^{\circ} \mathrm{C}$ around 

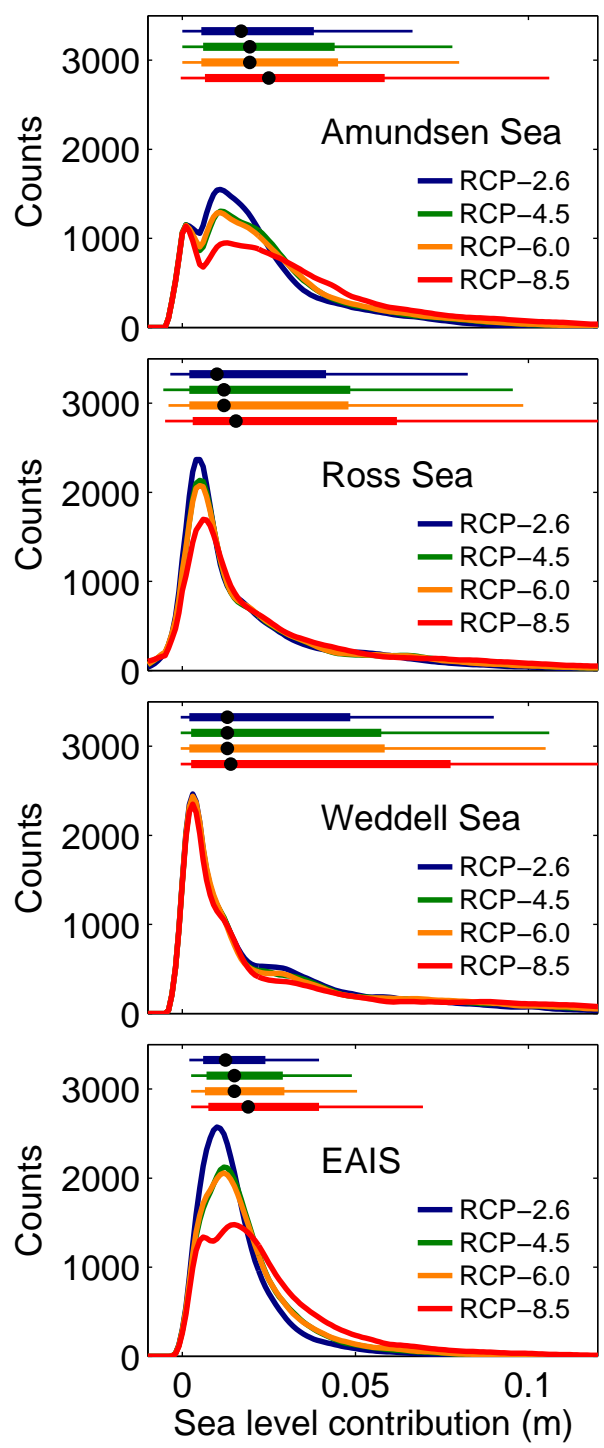

Figure 9. Probability density function for the sea-level contribution from basal-melt-induced ice discharge for each region for the year 2100. Different colours represent the four RCP scenarios. Thick horizontal lines at the top of each panel provide the $66 \%$ range of the distribution, the black dot is the median and the thin line the estimate of the $90 \%$ range. Amundsen has the highest median contributions though sectors are relatively similar. Scenario dependency is strongest for the Amundsen region and East Antarctica. The distributions are highly skewed towards higher sea-level contributions. Results are shown for the models with explicit ice-shelf representation only.

Antarctica (25th to 75th percentiles of ensemble, West and East respectively) between 1951-2000 and 2091-2100.

\subsection{Projected sea-level contribution for the past (1992-2011)}

Figure 7 shows the uncertainty range of the sea-level projection as obtained from this procedure for the sea-level change between 1992 and 2011 together with the range for this quantity as obtained from observations (Shepherd et al., 2012). The bars in the upper panels show that the likely range $(66 \%$ percentile) of the models with explicit ice-shelf representations (PennState-3D, PISM and SICOPOLIS) are in good agreement with the observed range. The median (black dot) of each model is within the observed range. The middle panel shows that the time delay plays an important role. The likely range obtained from the models with explicit ice-shelf representation (denoted shelf models for simplicity) is almost identical to the observed range when the time delay is accounted for (dark red) while it reaches higher than the observed range without the time delay (dark blue). While we cannot claim that the ocean models or the ice-sheet models are capable of simulating the specific (and largely unknown) events that resulted in the sea-level contribution from Antarctica between 1992 and 2011, the observed signal corresponds well with our estimated range.

\subsection{Results for the different basins and different models}

Figure 8 shows the uncertainty range of the projected contribution from the different oceanic sectors comprising uncertainty in climate and ocean circulation. While the individual time series will differ from the non-probabilistic projections with the ocean models, FESOM and BRIOS, the order of magnitude of the range of the sea-level contribution is the same. For example, FESOM yields a particularly strong response in the Weddell sector when forced with the HadCM-3 model (dashed lines in Fig. 6) and BRIOS a weak response when forced with ECHAM-5. The response of the models from the downscaled global simulations covers this range. While we find the largest median response in the Amundsen Sea sector which forces the Pine Island and Thwaites glaciers, the contributions of all sectors are relatively similar with a scatter of the median from 0.01 to $0.03 \mathrm{~m}$ (Fig. 9). Note, however, that the contributions from the different regions are not independent and thus the median of the full ensemble cannot necessarily be obtained as the sum of the individual medians of the basins. The histogram of the icedischarge contribution for the year 2100 in Fig. 9 shows the strongly skewed probability distribution.

The total ice discharge varies strongly between the different ice-sheet models (Fig. 10) as can be expected from the differences in the response functions of Fig. 3. The weakest ice loss is projected from the SICOPOLIS model while the strongest signal is obtained from PennState-3D. As the three models with explicit representation of ice shelves (SICOPOLIS, PennState-3D, PISM) span the full range of responses within the constraints of the applied methodology, they are 


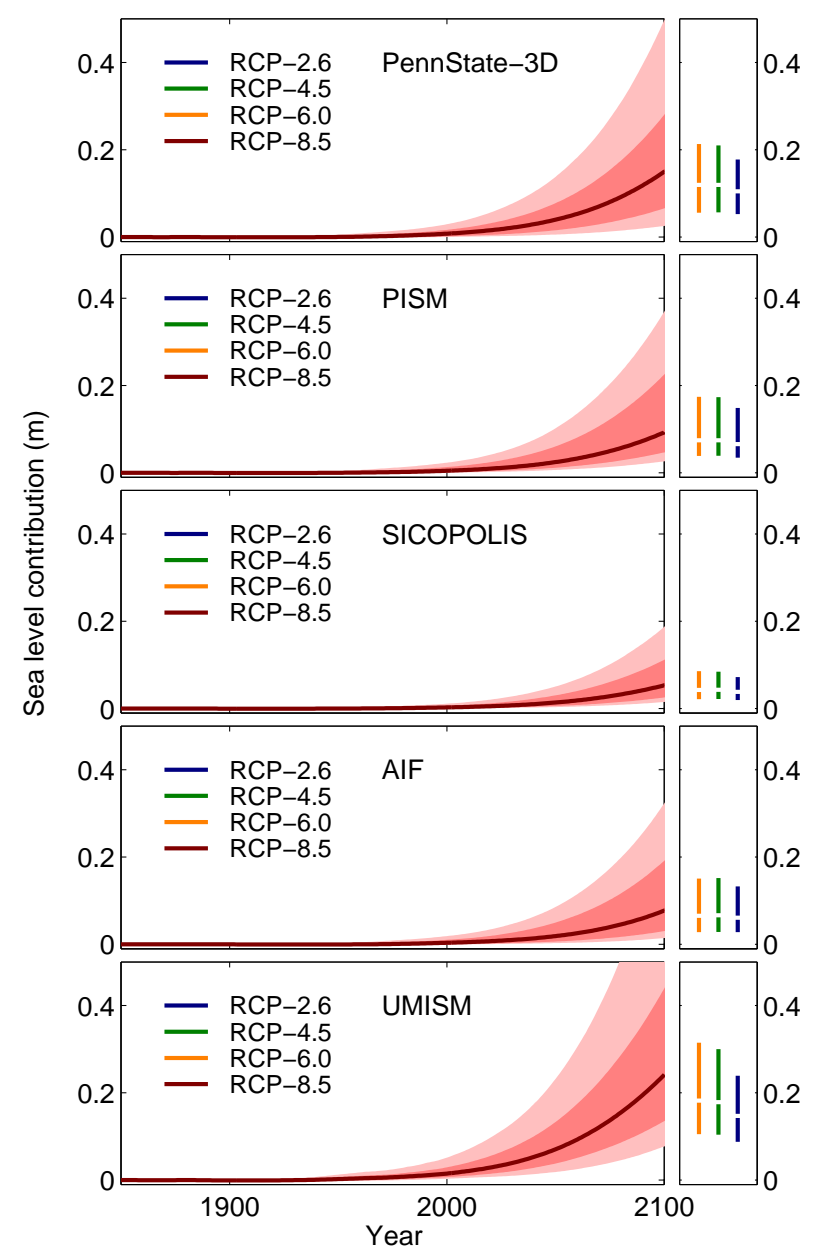

Figure 10. Uncertainty range of contributions to global sea level from basal-melt induced ice discharge from Antarctica for the different ice-sheet models. Lines, shading and colour coding as in Fig. 8. Coloured bars at the right show the other scenarios' $66 \%$ range intersected by the median.

the base of our further analysis. The two models without explicit ice-shelf dynamics, AIF and UMISM, however, yield responses of the same order of magnitude. The stronger response of the UMISM model is due to the fact that basal melt was applied along the entire coastline of Antarctica (Fig. 5), which is likely an overestimation of the real situation. While there is a clear dependence on the climatic scenario especially for the $90 \%$ percentile, the uncertainty between different ice-sheet models is comparable to the scenario spread. The strongest difference between models with and without explicit ice-shelf representation is observed in East Antarctica (dashed line in Fig. 8 provides the range for all models). The difference results mainly from the strong contribution of the UMISM model which assumes basal melt along the entire coastline.
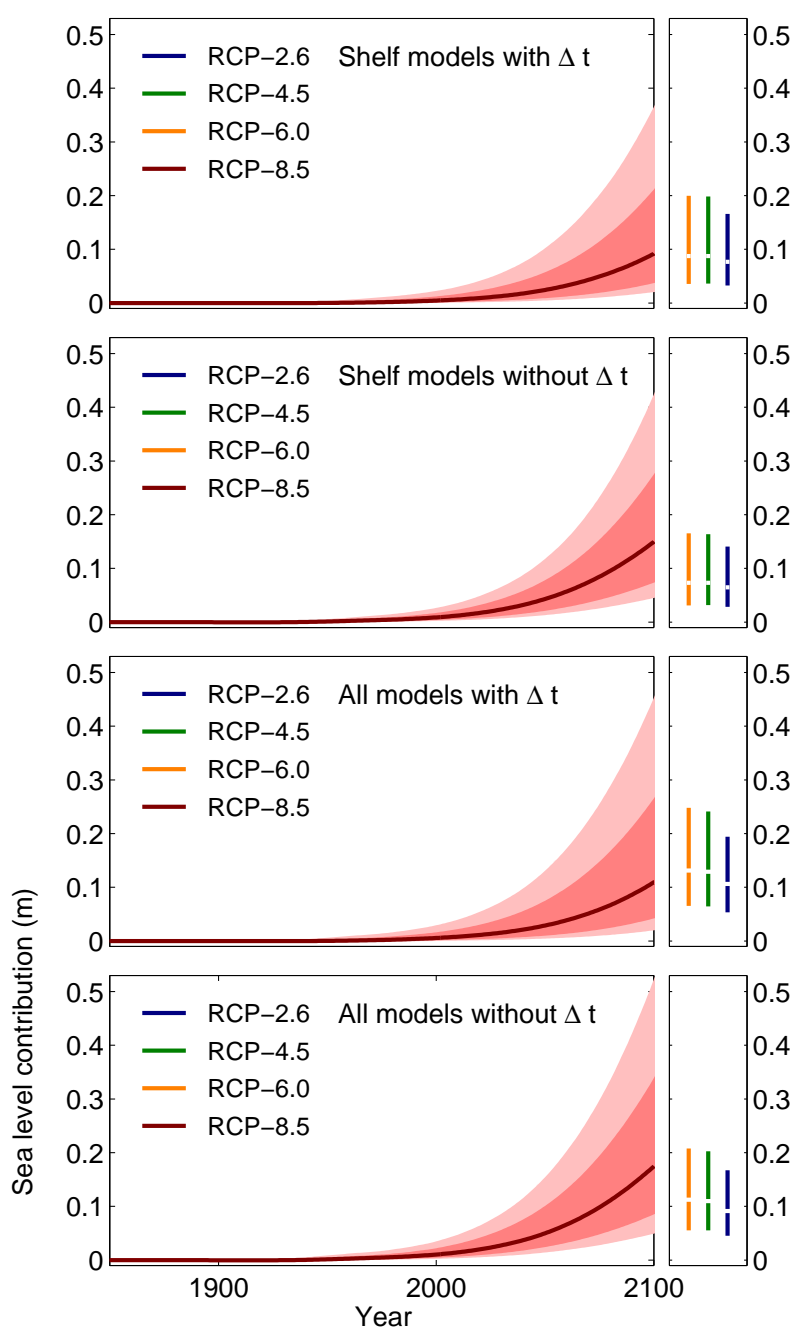

Figure 11. Uncertainty range of contributions to global sea level from basal ice-shelf melt induced ice discharge from Antarctica including climate-, ocean- and ice-sheet model uncertainty. Lines, shading and colour coding as in Fig. 8. Estimates with and without the time delay between global mean surface air temperature and subsurface ocean temperature (Tables 2-5) are presented. Shelf models are those ice-sheet models with explicit representation of ice shelves.

\subsection{Scenario dependence}

The full uncertainty range including climate-, ocean- and ice-sheet-model spread shows large uncertainty increasing with time along the 21 st century projections (Fig. 11). While model uncertainty is large, there is a scenario dependence which is visible in the median and the $66 \%$ percentile but most prominent for the $90 \%$ percentile of the distribution (Table 6). This scenario dependence is independent of the selection of the ice-sheet models or the inclusion of the time lag in the scaling of subsurface ocean temperatures (Fig. 12 and Table 6). The scenario dependence is not surprising since it is inherent in the applied procedure. It was assumed that 
the sea-level contribution is driven by the temperature increase in the atmosphere. Any natural variability in the atmosphere, ocean or the ice sheet was not taken into account. Given this methodological constraint, the scenario dependence is relatively small on these short timescales, especially since it seems that on longer timescales the contribution from Antarctica may depend significantly on the warming level (e.g. Levermann et al., 2013). The results are summarized in Fig. 13. All distributions are significantly skewed towards high sea-level contributions. This skewness strongly influences the median of the distributions as well as the 66 and $90 \%$ ranges. Consequently the median is not the value with the highest probability. The large tails makes an estimate of the $90 \%$ range, i.e. the very likely range as denoted by the IPCC-AR5 (IPCC, 2013), very uncertain.

\section{Conclusion and discussions}

The aim of this study is to estimate the range of the potential sea-level contribution caused by future ice discharge from Antarctica that can be induced by ocean warming within the 21 st century within the constraints of the models and the methodological approach. To this end, we include the full range of climatic forcing with climate models that yield practically no warming of the Southern Ocean subsurface (e.g. IPSL) to extreme cases with more than $2{ }^{\circ} \mathrm{C}$ of warming at the entrance of the ice-shelf cavities under the strongest warming scenario (Fig. 4).

In constructing the method using linear response theory, the uncertainty ranges comprising climatic, oceanic and icedynamical uncertainty show a dependence on the global climate-change scenario (Table 6), especially for the tails of the distribution, e.g. the $95 \%$ percentile. For the RCP-2.6 which was designed to result in a median increase in global mean temperature below $2{ }^{\circ} \mathrm{C}$ in most climate models, the $66 \%$ range of ice loss is $0.02-0.14 \mathrm{~m}$ around a median of $0.07 \mathrm{~m}$ in units of global mean sea-level rise. This range increases to $0.04-0.21 \mathrm{~m}$ for RCP-8.5 with a median contribution of $0.09 \mathrm{~m}$. This compares to a likely range of -0.01 to $0.16 \mathrm{~m}$ for the dynamic Antarctic discharge until 2100 in the latest assessment report of the IPCC (Church et al., 2013). While the entire range was derived from a number of individual studies, the upper limit was mainly based on a probabilistic approach without specific accounting for the warming induced forcing Little et al. (2013a, b). This caused the limit to be independent of the scenario even though it was stated in the report that it is expected that the contribution will depend on the level of warming induced. It was further stated that this likely range can be exceed by several decimetres if the marine parts of the Antarctic ice sheet become unstable.

Our results are based on the three models with explicit representation of ice-shelf dynamics. The strongest difference to the ice-shelf models arises in the UMISM model which applies melting along the entire coastline. For the main analysis
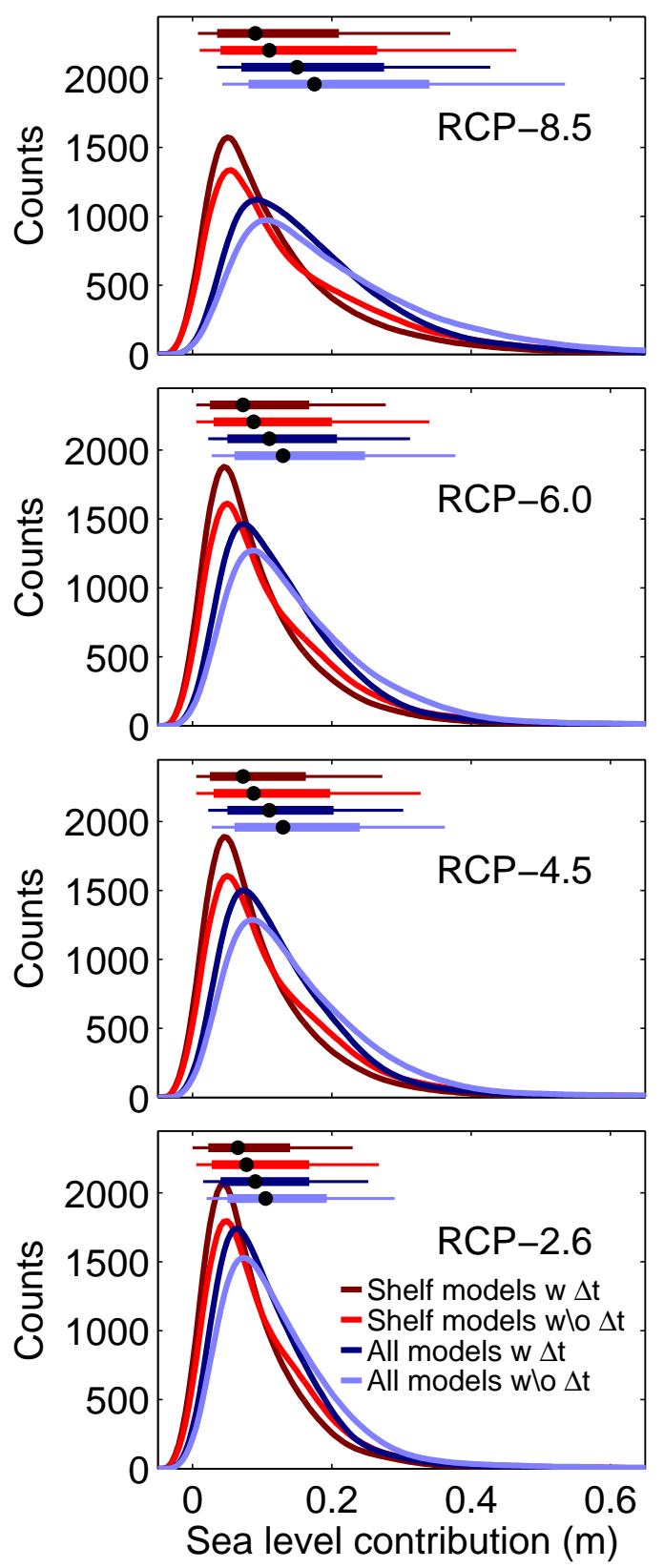

Figure 12. Uncertainty range including climate, ocean and icesheet uncertainty. Different colours represent different setups for the total sea-level contribution from basal ice-shelf melt induced ice discharge for the year 2100. Different panels provide estimates for the four RCP scenarios. Red curves in each panel show the three models with explicit representation of ice shelves (PennState-3D, PISM, SICOPOLIS). Blue curves show all models. Dark colours represent simulations using the time delay of Tables 2-5. Light coloured lines give distributions without time lag. All distributions are highly skewed towards high sea-level contributions which strongly influences the median (black dot), the $66 \%$ range (thick horizontal line at top) and the $90 \%$ range (thin horizontal line at top). The scenario dependence of each of these estimates is also visible in the number provided in Table 6. 

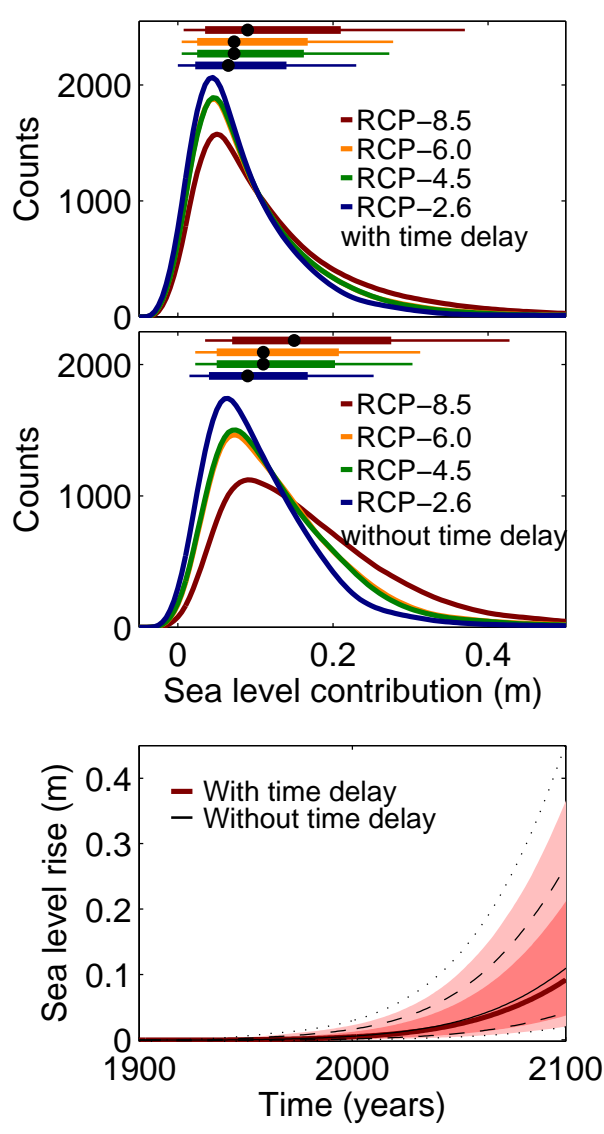

Figure 13. Uncertainty range including climate, ocean and icesheet uncertainty for the year 2100 . Different colours represent different scenarios using the three models including an explicit representation of ice shelves (PennState-3D, PISM, SICOPOLIS). The upper panel shows the results with time delay as listed in Tables 25. The middle panel shows the results without this time delay. All distributions are highly skewed towards high sea-level contributions which strongly influences the median, the $66 \%$ range (thick horizontal line at the top of the panel) and the $90 \%$ range (thin horizontal line at the top of the panel). The scenario dependence is strongest in the higher percentile of the distribution as also visible in the numbers provided in Table 6 . The lower panel shows the corresponding time series of the median, the $66 \%$ and the $90 \%$ percentile of the distribution with and without time delay.

the models with explicit ice-shelf representation were selected for three main reasons: first, these models allowed a direct application of the central forcing, i.e. basal ice-shelf melting, without further parameterization of the effect of the basal ice-shelf melting on the ice flow. Second, these models capture the evolution of the ice-shelf area underneath which the melting takes place and third, the projected ice loss from Antarctica for the historic period of 1992 to 2011 agrees with observed contribution within the observational uncertainty.
It has to be noted that the ice-sheet models as well as the climate models used here are coarse in horizontal model resolution. At this resolution the ice-sheet models are not able to simulate the benchmark behaviour of the MISMIP intercomparison projects (Pattyn et al., 2012, 2013). Two of the models used (PennState-3D and PISM) are able to simulate the grounding line behaviour in accordance with analytic solutions or the full-Stokes solution in MISMIP when using a significantly higher resolution (around $1 \mathrm{~km}$ ) than applied for the SeaRISE experiments (Pattyn et al., 2013; Feldmann et al., 2014). However, for continent-scale simulations, these high resolutions remain a challenge for ice-sheet models due to either the high computational costs or inadequate data sets, such as poorly known bedrock topography in the vicinity of grounding lines.

Furthermore, a number of physical processes that might be relevant for Antarctica's future contribution are not included in these models. Here we name only a few, but this list is most likely not complete because modelling the effect of basal topography, surface melt and interaction between the ice-sheet-shelf system and the ocean is still far from sufficient. For example, the effect of ice calving from ice shelves, but potentially even more importantly, from ice sheets into the ocean (Bassis and Jacobs, 2013; Levermann et al., 2012; Bassis, 2011; Walter et al., 2010) is not properly represented in most models. The effect of changes in surface properties and resulting changes in basal lubrication or ice rheology are either not included or likely not sufficiently represented (e.g. Box et al., 2012; Borstad et al., 2012; Cathles et al., 2011). Feedbacks from the ice melt to ocean circulation and the sea ice as well as possible water intrusion and interaction with the sediment are generally not represented (e.g. Gomez et al., 2013; Muto et al., 2013; Macayeal et al., 2012; Walter et al., 2012; Gomez et al., 2010; Hattermann and Levermann, 2010; Howat et al., 2010). While the focus of this study is the role of the uncertainty in external forcing, the resolutionbased deficiencies as well as the missing physical processes in the models need to be taken into account when interpreting the results.

At the same time, it needs to be noted that the uncertainty estimates presented are limited to the 21 st century. According to the 19 comprehensive climate models applied, the atmospheric warming arrives at the entrance of the ice-shelf cavities with a time delay of several decades. We apply a broad interval of coefficients to translate this time-delayed temperature increase into basal melt rates. The ice sheet responds to the higher melt rates with an increase of the ice flux across the grounding line. In some places this increased flux leads to a thinning upstream of the grounding line that is sufficiently strong to let the grounding line retreat. The three models applied are capable of simulating and show grounding line retreat in response to the climatic forcing applied. However, the signal from the enhanced ice flux across the grounding line dominates in this study. It needs to be noted that our estimates may not cover the full contribution from 

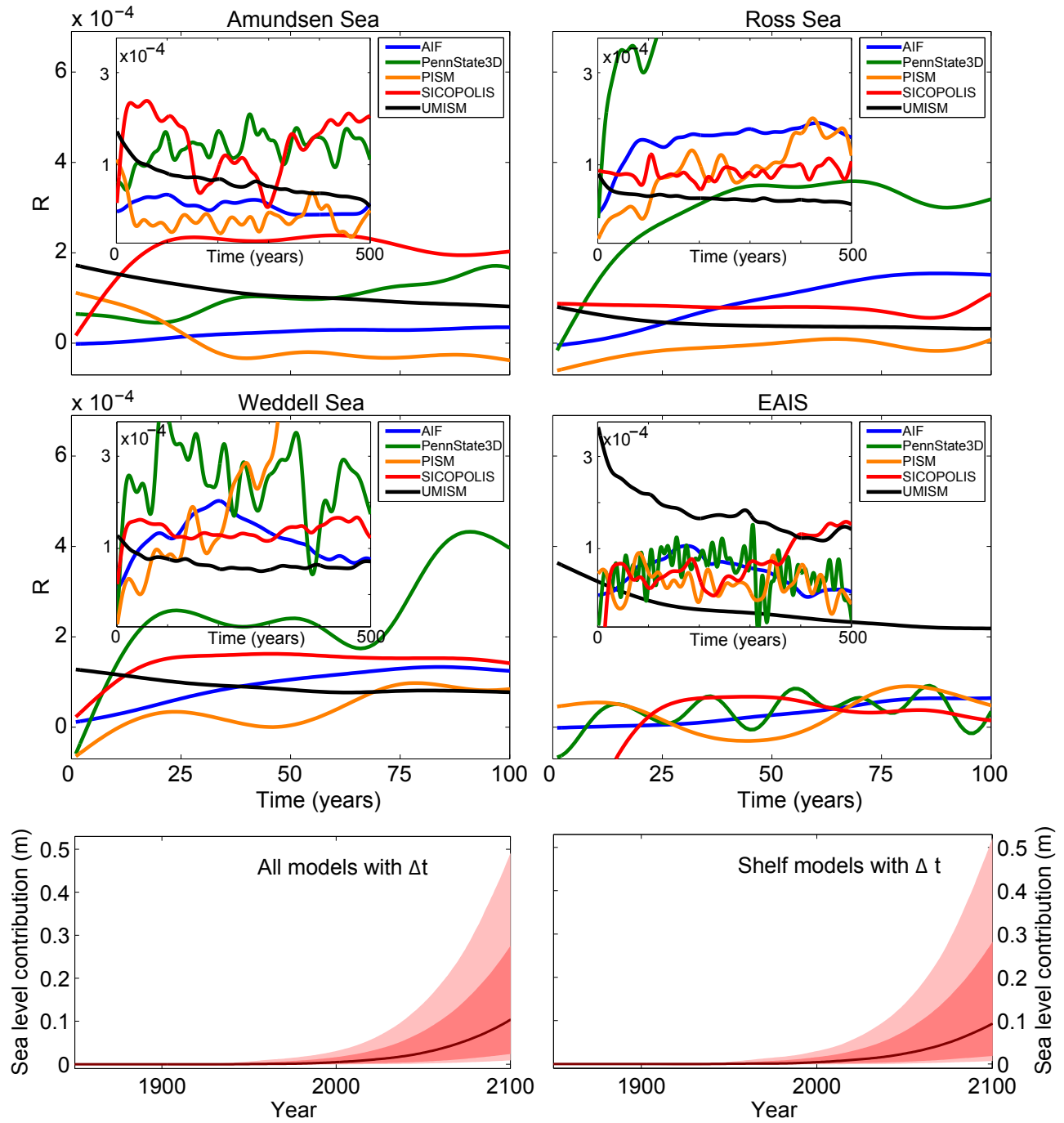

Figure 14. Response functions as obtained from the M1 experiment of the SeaRISE intercomparison with an additional uniform basal ice-shelf melting of $2 \mathrm{~m} \mathrm{a}^{-1}$. The upper four panels correspond to Fig. 3. The lower two panels show the uncertainty range in sea-level projections with the M1 response functions from above. The ranges obtained are very similar to the ranges obtained with the M2 response functions as shown in Fig. 11. While the response functions are very different for the M1 experiment compared to the M2 experiment, the projected ranges of sea-level rise are similar which is consistent with the fact that the uncertainty arises mainly from the uncertainty in the external forcing of the ice sheets.

consecutive, potentially self-accelerating grounding line retreat which may be significant (Favier et al., 2014; Joughin et al., 2014; Rignot et al., 2014; Mengel and Levermann, 2014).

However, the largest uncertainty in the future sea-level contribution estimated in this study arises from the uncertainty in the external forcing and here in particular from the uncertainty in the physical climate system, not in the socioeconomic pathways. This may arise due to the fact that only few ice-sheet models were applied compared to the large number of climate models and warming paths. Further studies are needed to assess whether large ice-sheet uncertainty arises with higher-resolution ice-sheet models. The signifi- cant uncertainty in surface warming that is associated with each emission scenario (RCP) translates into a subsurface oceanic warming where additional uncertainty in magnitude and timing arises. This oceanic warming at the entrance of the ice-shelf cavities then leads to sub-shelf melting which is subject to significant uncertainty. We here applied the full interval of observed sub-shelf melting sensitivities as obtained from the observational literature. The combination of all of these uncertain processes is then applied as an external forcing to the continental ice-sheet models. While the models need to be coarse in resolution in order to be able to model the entire continent, the main uncertainty in this study arises from the uncertainty in forcing not from the ice-sheet models. 
Internal variability was not accounted for, neither in the atmosphere nor in the ocean or ice-sheet models. This is due to the coarse resolution of the applied models and may significantly influence the contribution for the 21 st century (e.g. Hellmer et al., 2012).

The linear response approach sets further limits to the interpretation of our results. A significant response time of the sea-level-relevant ice flow to basal ice-shelf melting will be multi-decadal or longer which justifies the use of a linear response function to represent the full non-linear dynamics. A clear shortcoming is, however, that the method is not capable of capturing self-amplification processes within the ice. As a consequence an irreversible grounding line motion will be captured only when it is forced and not if it is merely triggered by the forcing and then self-amplifies. Thus, if the ice loss due to an instability is faster than due to the external forcing, then this additional ice loss will not be captured properly by the linear response theory. It is hypothesized that this is particularly relevant for weak forcing scenarios in which an instability might be triggered but the directly forced ice loss is weak. It might be less relevant for strong forcing scenarios like the RCP-8.5 when the forcing might dominate the dynamics.

Changes in the geometry of the ice-shelf cavity and salinity changes due to meltwater cannot be accounted for in a systematic way here. While the three ice-sheet models with ice-shelf representation within the limitation of their resolution incorporate dynamic shelf evolution, the geometry changes cannot feed back to the ocean circulation in our linear response approach. The computation of the basal iceshelf melt anomalies from the temperature anomalies is simplified as it excludes salinity changes. However, the simplification well approximates the dominating dynamics as the effect of salinity anomalies is small (Payne et al., 2007). To account for the feedbacks between ice thickness and salinity changes due to meltwater and the ocean circulation, interactive coupling of ice shelves models and global climate models is needed. As dynamic ice-shelf models are not implemented in the CMIP-5 climate models applied, the feedbacks cannot be reliably projected within the probabilistic approach taken here. We do not account for melt patterns underneath the ice shelves as basal melt rates are applied uniformly. While it has been shown that the melting distribution matters for the ice-sheet response (Walker et al., 2008; Gagliardini et al., 2010), it is beyond the scope of this study as a dynamic ocean model is not applied. The melt coefficients applied here were derived for an ice-shelf average and new uncertainty would be introduced with a spatially dependent melt coefficient.
As discussed above, a time lag between the oceanic temperature change and the change in global mean temperature is physically reasonable and applied in our projections. However, the correlation between surface warming and subsurface temperature change improves only marginally when introducing the time lag and it is not clear whether smallscale processes may accelerate the heat transport at finer resolution (Hellmer et al., 2012). It is thus worthwhile to consider the ice loss without a time lag (Fig. 11b). If the basal ice-shelf melt rates are applied immediately, the $66 \%$ range of the sea-level contribution increases from 0.04-0.21 to $0.07-0.28 \mathrm{~m}$ for RCP-8.5. The simulations with the highresolution finite-element ocean model FESOM and the regional ocean model BRIOS (Fig. 6) illustrate that abrupt ocean circulation changes can have strong influence on the basal melt rates (Hellmer et al., 2012). The comparably coarse-resolution ocean components of the CMIP-5 global climate models are unlikely to resolve such small-scale changes. Estimates such as those presented here will thus be dominated by basin-scale temperature changes of the interior ocean.

The probabilistic approach applied here assumes a certain interdependence of the different uncertainties. The global climatic signal is selected independently from the oceanic scaling coefficient. However, the range of scaling coefficients is derived from the correlation within the different CMIP5 models. The ice-sheet uncertainty is again independent of the other two components. While there are other methods to combine the uncertainties, we find no clear way of judging which method is superior.

The ice loss computed here is a response entirely to enhanced basal ice-shelf melting. There are other potential changes in the boundary conditions and dynamics of the ice sheet such as softening through ice warming and enhanced basal sliding as well as abrupt ice-shelf disintegration (not necessarily induced by basal ice-shelf melting) which might play a significant role in future ice discharge from Antarctica.

The method presented here can easily be applied to other ice-sheet models with improved dynamical representation as they become available. This study is merely a first step towards comprising the full range of forcing uncertainty into an estimate of the future sea-level contribution from Antarctica. 
Appendix A: Linear response function derived from SeaRISE M1 experiment

Figure 14 shows the response functions as obtained from the $\mathrm{M} 1$ experiment with $2 \mathrm{~m} \mathrm{a}^{-1}$ of additional basal ice-shelf melting. Comparison with Fig. 3 shows significant differences between the response functions obtained from the M1 and $\mathrm{M} 2$ experiments.

The lower panels of Fig. 14 show, however, that the uncertainty range of the sea-level projection is very similar to the projections obtained with the M2 experiment (Fig. 11). This illustrates the fact that the uncertainty range is dominated by the external forcing of the ice sheets, while the response functions provide merely the magnitude of the ice-sheet response to the forcing. For the ultimate uncertainty range, it is herein not crucial whether the response function of one specific model is different for the M1 and the M2 experiments as long as the range of responses spanned by all three models is similar. This supports the use of the probabilistic approach taken in this study. 
Acknowledgements. R. Winkelmann and M. A. Martin were funded by the German federal ministry of education and research (BMBF grant 01LP1171A). M. Meinshausen was funded by the Deutsche Bundesstiftung Umwelt. R. Greve and T. Sato were supported by a Grant-in-Aid for Scientific Research A (no. 22244058) from the Japan Society for the Promotion of Science (JSPS). S. Nowicki, R. A. Bindschadler, and W. L. Wang were supported by the NASA Cryospheric Science program (grants 281945.02.53.02.19 and 281945.02.53.02.20). K. Frieler was supported by the German Federal Ministry for the Environment, Nature Conservation and Nuclear Safety (11_II_093_Global_A_SIDS and LDCs). H. H. Hellmer, A. J. Payne and R. Timmermann were supported by the ice2sea programme from the European Union 7th Framework Programme, grant no. 226375.

Edited by: M. Huber

\section{References}

Albrecht, T., Martin, M. A., Winkelmann, R., Haseloff, M., and Levermann, A.: Parameterization for subgrid-scale motion of ice-shelf calving fronts, The Cryosphere, 5, 35-44, doi:10.5194/tc-5-35-2011, 2011.

Alley, R., Berntsen, T., Bindoff, N. L., Chen, Z., Chidthaisong, A., Friedlingstein, P., Hegerl, G., Heimann, M., Hewitson, B., Hoskins, B., Joos, F., Jouzel, J., Kattsov, V., Lohmann, U., Manning, M., Matsuno, T., Molina, M., Nicholls, N., Overpeck, J., Qin, D., Ramaswamy, V., Ren, J., Rusticucci, M., Solomon, S., Somerville, R., Stocker, T. F., Stott, P., Stouffer, R. J., Whetton, P., Wood, R. A., Wratt, D., Arblaster, J., Brasseur, G., Christensen, J. H., Denman, K., Fahey, D. W., Forster, P., Jansen, E., Jones, P. D., Knutti, R., Treut, H. L., Lemke, P., Meehl, G., Mote, P., Randall, D., Stone, D. A., Trenberth, E., Willebrand, J., and Zwiers, F.: Climate Change 2007: The Physical Science Basis. Contribution of Working Group I to the Fourth Assessment Report of the Intergovernmental Panel on Climate Change, Cambridge University Press, Cambridge, UK and New York, NY, USA, 2007.

Aschwanden, A., Bueler, E., Khroulev, C., and Blatter, H.: An enthalpy formulation for glaciers and ice sheets, J. Glaciol., 58, 441-457, doi:10.3189/2012JoG11J088, 2012.

Assmann, K. M., Hellmer, H. H., and Jacobs, S. S.: Amundsen Sea ice production and transport, J. Geophys. Res., 110, 311-337, 2005.

Bamber, J. L., Riva, R. E. M., Vermeersen, B. L. A., and LeBrocq, A. M.: Reassessment of the Potential Sea-Level Rise from a Collapse of the West Antarctic Ice Sheet, Science, 324, 901-903, doi:10.1126/science.1169335, 2009.

Bassis, J. N.: The statistical physics of iceberg calving and the emergence of universal calving laws, J. Geol., 57, 3-16, 2011.

Bassis, J. N. and Jacobs, S.: Diverse calving patterns linked to glacier geometry, Nat. Geosci., 6, 1-4, doi:10.1038/ngeo1887, 2013.

Beckmann, A., Hellmer, H. H., and Timmermann, R.: A numerical model of the Weddell Sea: Large-scale circulation and water mass distribution, Geophys. Res. Lett., 104, 23375-23391, 1999.
Bindschadler, R. A., Nowicki, S., Abe-Ouchi, A., Aschwanden, A., Choi, H., Fastook, J., Granzow, G., Greve, R., Gutowski, G., Herzfeld, U., Jackson, C., Johnson, J., Khroulev, C., Levermann, A., Lipscomb, W. H., Martin, M. A., Morlighem, M., Parizek, B. R., Pollard, D., Price, S. F., Ren, D., Saito, F., Sato, T., Seddik, H., Seroussi, H., Takahashi, K., Walker, R., and Wang, W. L.: Icesheet model sensitivities to environmental forcing and their use in projecting future sea level (the SeaRISE project), J. Glaciol., 59, 195-224, doi:10.3189/2013JoG12J125, 2013.

Borstad, C. P., Khazendar, A., Larour, E., Morlighem, M., Rignot, E., Schodlok, M. P., and Seroussi, H.: A damage mechanics assessment of the Larsen B ice shelf prior to collapse: Toward a physically-based calving law, Geophys. Res. Lett., 39, L18502, doi:10.1029/2012GL053317, 2012.

Box, J. E., Fettweis, X., Stroeve, J. C., Tedesco, M., Hall, D. K., and Steffen, K.: Greenland ice sheet albedo feedback: thermodynamics and atmospheric drivers, The Cryosphere, 6, 821-839, doi:10.5194/tc-6-821-2012, 2012.

Bueler, E. and Brown, J.: The shallow shelf approximation as a sliding law in a thermomechanically coupled ice sheet model, J. Geophys. Res., 114, F03008, doi:10.1029/2008JF001179, 2009.

Cathles, L. M., Abbot, D. S., Bassis, J. N., and MacAyeal, D. R.: Modeling surface-roughness/solar-ablation feedback: application to small-scale surface channels and crevasses of the Greenland ice sheet, Ann. Glaciol., 52, 99-108, doi:10.3189/172756411799096268, 2011.

Church, J., Clark, P., Cazenave, A., Gregory, J., Jevrejeva, S., Levermann, A., Merrifield, M., Milne, G., Nerem, R., Nunn, P., Payne, A., Pfeffer, W., Stammer, D., and Unnikrishnan, A.: Sea Level Change, in: Climate Change 2013: The Physical Science Basis. Contribution of Working Group I to the Fifth Assessment Report of the Intergovernmental Panel on Climate Change, Cambridge University Press, Cambridge, UK and New York, NY, USA, 2013.

Danilov, S., Kivman, G., and Schröter, J.: A finite element ocean model: principles and evaluation, Ocean Modell., 6, 125-150, 2004.

Danilov, S., Kivman, G., and Schröter, J.: Evaluation of an eddypermitting finite-element ocean model in the North Atlantic, Ocean Modell., 10, 35-49, 2005.

Fastook, J. L.: A map-plane finite-element program for ice sheet reconstruction: A steady-state calibration with Antarctica and a reconstruction of the Laurentide Ice Sheet for 18,000 BP, in: Computer Assisted Analysis and Modeling on the IBM 3090, edited by: Brown, H. U., IBM Scientific and Technical Computing Dept., White Plains, N.Y., 1990.

Fastook, J. L.: The finite-element method for solving conservation equations in glaciology, Comput. Sci. Eng., 1, 55-67, 1993.

Fastook, J. L. and Chapman, J.: A map plane finite-element model: Three modeling experiments, J. Glaciol., 35, 48-52, 1989.

Fastook, J. L. and Hughes, T. J.: Changing ice loads on the Earth's surface during the last glacial cycle, in: Glacial Isostasy, Sea-Level and Mantle Rheology, Series C: Mathematical and Physical Sciences, Vol. 334, edited by: Sabadini, R., Lambeck, K., and Boschi, E., Kluwer Academic Publishers, Dordrecht/Boston/London, 1990.

Fastook, J. L. and Prentice, M.: A finite-element model of Antarctica: Sensitivity test for meteorological mass balance relationship, J. Glaciol., 40, 167-175, 1994. 
Fastook, J. L., Head, J. W., Forget, F., Madeleine, J.-B., and Marchant, D. R.: Evidence for Amazonian northern mid-latitude regional glacial landsystems on Mars: Glacial flow models using GCM-driven climate results and comparisons to geological observations, Icarus, 216, 23-39, 2011.

Fastook, J. L., Head, J. W., Marchant, D. R., Forget, F., and Madeleine, J.-B.: Early Mars Climate Near the NoachianHesperian Boundary: Independent Evidence for Cold Conditions from Basal Melting of the South Polar Ice Sheet (Dorsa Argentea Formation) and Implications for Valley Network Formation, Icarus, 219, 25-40, 2012.

Favier, L., Durand, G., Cornford, S. L., Gudmundsson, G. H., Gagliardini, O., Gillet-Chaulet, F., Zwinger, T., Payne, A. J., and Le Brocq, a. M.: Retreat of Pine Island Glacier controlled by marine ice-sheet instability, Nat. Clim. Change, 4, 117-121, doi:10.1038/nclimate2094, 2014.

Feldmann, J., Albrecht, T., Khroulev, C., Pattyn, F., and Levermann, A.: Resolution-dependent performance of grounding line motion in a shallow model compared with a full-Stokes model according to the MISMIP3d intercomparison, J. Glaciol., 60, 353-360, doi:10.3189/2014JoG13J093, 2014.

Gagliardini, O., Durand, G., Zwinger, T., Hindmarsh, R. C. A., and Le Meur, E.: Coupling of ice-shelf melting and buttressing is a key process in ice-sheets dynamics, Geophys. Res. Lett., 37, L14501, doi:10.1029/2010GL043334, 2010.

Gladstone, R. M., Payne, A. J., and Cornford, S. L.: Parameterising the grounding line in flow-line ice sheet models, The Cryosphere, 4, 605-619, doi:10.5194/tc-4-605-2010, 2010.

Gomez, N., Mitrovica, J. X., Huybers, P., and Clark, P. U.: Sea level as a stabilizing factor for marine-ice-sheet grounding lines, Nat. Geosci., 3, 850-853, doi:10.1038/ngeo1012, 2010.

Gomez, N., Pollard, D., and Mitrovica, J. X.: A 3-D coupled ice sheet - sea level model applied to Antarctica through the last $40 \mathrm{ky}$, Earth and Planet. Sci. Lett., 384, 88-99, doi:10.1016/j.eps1.2013.09.042, 2013.

Good, P., Gregory, J. M., and Lowe, J. A.: A step-response simple climate model to reconstruct and interpret AOGCM projections, Geophys. Res. Lett., 38, 1703, doi:10.1029/2010GL045208, 2011.

Greve, R.: Thermomechanisches Verhalten polythermer Eisschilde - Theorie, Analytik, Numerik, Doctoral thesis, Department of Mechanics, Darmstadt University of Technology, Germany, Berichte aus der Geowissenschaft, Shaker Verlag, Aachen, Germany, 1995.

Greve, R.: Application of a polythermal three-dimensional ice sheet model to the Greenland ice sheet: Response to steadystate and transient climate scenarios, J. Climate, 10, 901-918, doi:10.1175/1520-0442(1997)010<0901:AOAPTD>2.0.CO;2, 1997.

Greve, R.: Relation of measured basal temperatures and the spatial distribution of the geothermal heat flux for the Greenland ice sheet, Ann. Glaciol., 42, 424-432, doi:10.3189/172756405781812510, 2005.

Greve, R. and Blatter, H.: Dynamics of Ice Sheets and Glaciers, Springer, 2009.

Hallegatte, S., Green, C., Nicholls, R. J., and Corfee-Morlot, J.: Future flood losses in major coastal cities, Nat. Clim. Change, 3, 802-806, doi:10.1038/nclimate1979, 2013.
Hattermann, T. and Levermann, A.: Response of Southern Ocean circulation to global warming may enhance basal ice shelf melting around Antarctica, Clim. Dynam., 34, 741-756, doi:10.1007/s00382-009-0643-3, 2010.

Hellmer, H. H.: Impact of Antarctic ice shelf basal melting on sea ice and deep ocean properties, Geophys. Res. Lett., 31, L10307, doi:10.1029/2004GL019506, 2004.

Hellmer, H. H. and Olbers, D. J.: A Two-Dimensional Model for the Thermohaline Circulation Under an Ice Shelf, Antarctic Sci., 1, 325-336, 1989.

Hellmer, H. H., Jacobs, S. S., and Jenkins, A.: Oceanic erosion of a floating Antarctic glacier in the Amundsen Sea, in: Ocean, ice and atmosphere: interactions at Antarctic Continental margin, edited by: Jacobs, S. S. and Weiss, R., Vol. 75 of Antarctic research series. American Geophysical Union, Washington, DC, 83-100, 1998.

Hellmer, H. H., Kauker, F., Timmermann, R., Determann, J., and Rae, J.: Twenty-first-century warming of a large Antarctic iceshelf cavity by a redirected coastal current, Nature, 485, 225228, doi:10.1038/nature11064, 2012.

Hibler, W. D., III: A dynamic-thermodynamic sea ice model, J. Phys. Oceanogr., 9, 815-846, 1979.

Hinkel, J., Lincke, D., Vafeidis, A. T., Perrette, M., Nicholls, R. J., Tol, R. S. J., Marzeion, B., Fettweis, X., Ionescu, C., and Levermann, A.: Coastal flood damage and adaptation costs under $21 \mathrm{st}$ century sea-level rise., Proc. Natl. Acad. Sci. USA, 111, 3292-7, doi:10.1073/pnas.1222469111, 2014.

Holland, D. M. and Jenkins, A.: Modeling Thermodynamic IceOcean Interactions at the Base of an Ice Shelf, J. Climate, 29, 1787-1800, 1999.

Holland, P. R., Jenkins, A., and Holland, D. M.: The Response of Ice Shelf Basal Melting to Variations in Ocean Temperature, J. Climate, 21, 2558-2572, 2008.

Howat, I. M., Box, J. E., Ahn, Y., Herrington, A., and McFadden, E. M.: Seasonal variability in the dynamics of marineterminating outlet glaciers in Greenland, J. Glaciol., 56, 601613, doi:10.3189/002214310793146232, 2010.

Hutter, K.: Theoretical Glaciology; Material Science of Ice and the Mechanics of Glaciers and Ice Sheets, D. Reidel Publishing Company, Dordrecht, The Netherlands, 1983.

Huybrechts, P., Goelzer, H., Janssens, I., Driesschaert, E., Fichefet, T., Goosse, H., and Loutre, M.-F.: Response of the Greenland and Antarctic Ice Sheets to Multi-Millennial Greenhouse Warming in the Earth System Model of Intermediate Complexity LOVECLIM, Surv. Geophys., 32, 397-416, 2011.

IPCC: Climate Change 2013: The Physical Science Basis. Contribution of Working Group I to the Fifth Assessment Report of the Intergovernmental Panel on Climate Change, Cambridge University Press, Cambridge, UK and New York, NY, USA, 2013.

Jenkins, A.: Ice shelf basal melting: Implications of a simple mathematical model, Tech. Rep. FRISP Rep. 5, 1991.

Johnson, J. and Fastook, J. L.: Northern Hemisphere glaciation and its sensitivity to basal melt water, Quaternary Int., 95-96, 65-74, 2002.

Joughin, I., Smith, B. E., and Medley, B.: Marine ice sheet collapse potentially under way for the Thwaites Glacier Basin, West Antarctica, Science (New York, N.Y.), 344, 735-738, doi:10.1126/science.1249055, 2014. 
Le Brocq, A. M., Payne, A. J., and Vieli, A.: An improved Antarctic dataset for high resolution numerical ice sheet models (ALBMAP v1), Earth System Sci. Data, 2, 247-260, doi:10.5194/essd-2-247-2010, 2010.

Le Meur, E. and Huybrechts, P.: A comparison of different ways of dealing with isostasy: examples from modelling the Antarctic ice sheet during the last glacial cycle, Ann. Glaciol., 23, 309-317, 1996.

Levermann, A., Albrecht, T., Winkelmann, R., Martin, M. A., Haseloff, M., and Joughin, I.: Kinematic first-order calving law implies potential for abrupt ice-shelf retreat, The Cryosphere, 6 , 273-286, doi:10.5194/tc-6-273-2012, 2012.

Levermann, A., Clark, P. U., Marzeion, B., Milne, G. A., Pollard, D., Radic, V., and Robinson, A.: The multimillennial sea-level commitment of global warming, Proc. Natl. Acad. Sci., 110, 13745-13750, doi:10.1073/pnas.1219414110, 2013.

Little, C. M., Oppenheimer, M., and Urban, N. M.: Upper bounds on twenty-first-century Antarctic ice loss assessed using a probabilistic framework, Nat. Clim. Change, 3, 654-659, doi:10.1038/nclimate1845, 2013a.

Little, C. M., Urban, N. M., and Oppenheimer, M.: Probabilistic framework for assessing the ice sheet contribution to sea level change., Proc. Natl. Acad. Sci. USA, 110, 3264-3269, 2013 b.

MacAyeal, D. R.: Large-scale ice flow over a viscous basal sediment: theory and application to ice stream B, Antarctica, J. Geophys. Res., 94, 4071-4087, 1989.

Macayeal, D. R., Freed-brown, J., Zhang, W. W., and Amundson, J. M.: The influence of ice melange on fjord seiches, Ann. Glaciol., 53, 45-49, doi:10.3189/2012/AoG60A027, 2012.

Martin, M. A., Winkelmann, R., Haseloff, M., Albrecht, T., Bueler, E., Khroulev, C., and Levermann, A.: The Potsdam Parallel Ice Sheet Model (PISM-PIK) - Part 2: Dynamic equilibrium simulation of the Antarctic ice sheet, The Cryosphere, 5, 727-740, doi:10.5194/tc-5-727-2011, 2011.

Marzeion, B. and Levermann, A.: Loss of cultural world heritage and currently inhabited places to sea-level rise, Environ. Res. Lett., 9, 034001, doi:10.1088/1748-9326/9/3/034001, 2014.

Meinshausen, M., Meinshausen, N., Hare, W., Raper, S. C. B., Frieler, K., Knutti, R., Frame, D. J., and Allen, M. R.: Greenhouse-gas emission targets for limiting global warming to $2^{\circ} \mathrm{C}$, Nature, 458, 1158-1162, 2009.

Meinshausen, M., Raper, S. C. B., and Wigley, T. M. L.: Emulating coupled atmosphere-ocean and carbon cycle models with a simpler model, MAGICC6 - Part 1: Model description and calibration, Atmos. Chem. Phys., 11, 1417-1456, doi:10.5194/acp11-1417-2011, 2011a.

Meinshausen, M., Smith, S., Calvin, K., Daniel, J., Kainuma, M., Lamarque, J.-F., Matsumoto, K., Montzka, S., Raper, S., Riahi, K., Thomson, A., Velders, G., and van Vuuren, D. P.: The RCP greenhouse gas concentrations and their extensions from 1765 to 2300, Clim. Change, 109, 213-241, doi:10.1007/s10584-0110156-z, $2011 \mathrm{~b}$.

Mengel, M. and Levermann, A.: Ice plug prevents irreversible discharge from East Antarctica, Nat. Clim. Change, 4, 451-455, doi:10.1038/NCLIMATE2226, 2014.

Mitrovica, J. X., Gomez, N., and Clark, P. U.: The Sea-Level Fingerprint of West Antarctic Collapse, Science, 323, p. 753, 2009.

Morland, L. W.: Thermomechanical balances of ice sheet flows, Geophys. Astrophys. Fluid Dynam., 29, 237-266, 1984.
Morland, L. W.: Unconfined ice-shelf flow, in: Dynamics of the West Antarctic Ice Sheet, edited by: van der Veen, C. J. and Oerlemans, J., 99-116, D. Reidel Publishing Company, Dordrecht, The Netherlands, 1987.

Moss, R. H., Edmonds, J. a., Hibbard, K. a., Manning, M. R., Rose, S. K., van Vuuren, D. P., Carter, T. R., Emori, S., Kainuma, M., Kram, T., Meehl, G. a., Mitchell, J. F. B., Nakicenovic, N., Riahi, K., Smith, S. J., Stouffer, R. J., Thomson, A. M., Weyant, J. P., and Wilbanks, T. J.: The next generation of scenarios for climate change research and assessment, Nature, 463, 747-56, doi:10.1038/nature08823, 2010.

Muto, A., Anandakrishnan, S., and Alley, R. B.: Subglacial bathymetry and sediment layer distribution beneath the Pine Island Glacier ice shelf, West Antarctica, modeled using aerogravity and autonomous underwater vehicle data, Ann. Glaciol., 54, 27-32, doi:10.3189/2013AoG64A110, 2013.

Nowicki, S., Bindschadler, R. A., Abe-Ouchi, A., Aschwanden, A., Bueler, E., Choi, H., Fastook, J., Granzow, G., Greve, R., Gutowski, G., Herzfeld, U., Jackson, C., Johnson, J., Khroulev, C., Larour, E., Levermann, A., Lipscomb, W. H., Martin, M. a., Morlighem, M., Parizek, B. R., Pollard, D., Price, S. F., Ren, D., Rignot, E., Saito, F., Sato, T., Seddik, H., Seroussi, H., Takahashi, K., Walker, R., and Wang, W. L.: Insights into spatial sensitivities of ice mass response to environmental change from the SeaRISE ice sheet modeling project I: Antarctica, J. Geophys. Res.-Earth Surf., 118, 1002-1024, doi:10.1002/jgrf.20081, 2013a.

Nowicki, S., Bindschadler, R. A., Abe-Ouchi, A., Aschwanden, A., Bueler, E., Choi, H., Fastook, J., Granzow, G., Greve, R., Gutowski, G., Herzfeld, U., Jackson, C., Johnson, J., Khroulev, C., Larour, E., Levermann, A., Lipscomb, W. H., Martin, M. A., Morlighem, M., Parizek, B. R., Pollard, D., Price, S. F., Ren, D., Rignot, E., Saito, F., Sato, T., Seddik, H., Seroussi, H., Takahashi, K., Walker, R., and Wang, W. L.: Insights into spatial sensitivities of ice mass response to environmental change from the SeaRISE ice sheet modeling project II: Greenland, J. Geophys. Res.-Earth Surf., 118, 1025-1044, doi:10.1002/jgrf.20076, 2013 b.

Parkinson, C. L. and Washington, W. M.: A large-scale numerical model of sea ice, J. Geophys. Res., 84, 311-337, 1979.

Pattyn, F., Schoof, C., Perichon, L., Hindmarsh, R. C. A., Bueler, E., de Fleurian, B., Durand, G., Gagliardini, O., Gladstone, R., Goldberg, D., Gudmundsson, G. H., Huybrechts, P., Lee, V., Nick, F. M., Payne, A. J., Pollard, D., Rybak, O., Saito, F., and Vieli, A.: Results of the Marine Ice Sheet Model Intercomparison Project, MISMIP, The Cryosphere, 6, 573-588, doi:10.5194/tc6-573-2012, 2012.

Pattyn, F., Perichon, L., Durand, G., Favier, L., Gagliardini, O., Hindmarsh, R. C., Zwinger, T., Albrecht, T., Cornford, S., Docquier, D., Fürst, J. J., Goldberg, D., Gudmundsson, G. H., Humbert, A., Hütten, M., Huybrechts, P., Jouvet, G., Kleiner, T., Larour, E., Martin, D., Morlighem, M., Payne, A. J., Pollard, D., Rückamp, M., Rybak, O., Seroussi, H., Thoma, M., and Wilkens, N.: Grounding-line migration in plan-view marine icesheet models: results of the ice2sea MISMIP3d intercomparison, J. Glaciol., 59, 410-422, doi:10.3189/2013JoG12J129, 2013. 
Payne, A. J., Holland, P. R., Shepherd, A. P., Rutt, I. C., Jenkins, A., and Joughin, I.: Numerical modeling of ocean-ice interactions under Pine Island Bay's ice shelf, J. Geophys. Res., 112, 10019, doi:10.1029/2006JC003733, 2007.

Pollard, D. and DeConto, R. M.: Modelling West Antarctic ice sheet growth and collapse through the past five million years, Nature, 458, 329-332, 2009.

Pollard, D. and DeConto, R. M.: A simple inverse method for the distribution of basal sliding coefficients under ice sheets, applied to Antarctica, The Cryosphere, 6, 953-971, doi:10.5194/tc-6953-2012, 2012.

Rignot, E., Mouginot, J., Morlighem, M., Seroussi, H., and Scheuchl, B.: Widespread, rapid grounding line retreat of Pine Island, Thwaites, Smith, and Kohler glaciers, West Antarctica, from 1992 to 2011, Geophys. Res. Lett., 41, 1576-1584, doi:10.1002/2013GL059069, 2014.

Sato, T.: Dynamics of the Antarctic ice sheet with coupled ice shelves, Ph.D. thesis, Graduate School of Environmental Science, Hokkaido University, Sapporo, Japan, available at: http: //tinyurl.com/GISRG42, 2012.

Sato, T. and Greve, R.: Sensitivity experiments for the Antarctic ice sheet with varied sub-ice-shelf melting rates, Ann. Glaciol., 53, 221-228, doi:10.3189/2012AoG60A042, 2012.

Schewe, J., Levermann, A., and Meinshausen, M.: Climate change under a scenario near $1.5^{\circ} \mathrm{C}$ of global warming: monsoon intensification, ocean warming and steric sea level rise, Earth Syst. Dynam., 2, 25-35, doi:10.5194/esd-2-25-2011, 2011.

Schoof, C.: Ice sheet grounding line dynamics: Steady states, stability, and hysteresis, J. Geophys. Res., 112, F03S28, doi:10.1029/2006JF000664, 2007.

Shepherd, A., Ivins, E. R., A, G., Barletta, V. R., Bentley, M. J., Bettadpur, S., Briggs, K. H., Bromwich, D. H., Forsberg, R., Galin, N., Horwath, M., Jacobs, S., Joughin, I., King, M. A., Lenaerts, J. T. M., Li, J., Ligtenberg, S. R. M., Luckman, A., Luthcke, S. B., McMillan, M., Meister, R., Milne, G., Mouginot, J., Muir, A., Nicolas, J. P., Paden, J., Payne, A. J., Pritchard, H., Rignot, E., Rott, H., Sorensen, L. S., Scambos, T. A., Scheuchl, B., Schrama, E. J. O., Smith, B., Sundal, A. V., van Angelen, J. H., van de Berg, W. J., van den Broeke, M. R., Vaughan, D. G., Velicogna, I., Wahr, J., Whitehouse, P. L., Wingham, D. J., Yi, D., Young, D., and Zwally, H. J.: A Reconciled Estimate of Ice-Sheet Mass Balance, Science, 338, 1183-1189, doi:10.1126/science.1228102, 2012.

Sidorenko, D., Wang, Q., Danilov, S., and Schröter, J.: FESOM under Coordinated Ocean-ice Reference Experiment forcing, Ocean Dynam., 61, 881-890, doi:10.1007/s10236-011-0406-7, 2011.

Taylor, K. E., Stouffer, R. J., and Meehl, G. A.: An overview of CMIP5 and the experiment design, B. Am. Meteorol. Soc., 93, 485-498, 2012.

Timmermann, R. and Hellmer, H. H.: Southern Ocean warming and increased ice shelf basal melting in the 21 st and 22 nd centuries based on coupled ice-ocean finite-element modelling, Ocean Dynam., 63, 1011-1026, doi:10.1007/s10236-013-0642-0, 2013.

Timmermann, R., Beckmann, A., and Hellmer, H. H.: Simulation of ice-ocean dynamics in the Weddell Sea 1: Model configuration and validation, J. Geophys. Res., 107, 3024, doi:10.1029/2000JC000741, 2002a.
Timmermann, R., Hellmer, H. H., and Beckmann, A.: Simulations of ice-ocean dynamics in the Weddell Sea 2. Interannual variability 1985-1993, J. Geophys. Res., 107, 3025, doi:10.1029/2000JC000742, 2002 b.

Timmermann, R., Danilov, S., Schröter, J., Böning, C., Sidorenko, D., and Rollenhagen, K.: Ocean circulation and sea ice distribution in a finite element global sea ice - ocean model, Ocean Modell., 27, 114-129, doi:10.1016/j.ocemod.2008.10.009, 2009.

Timmermann, R., Le Brocq, A., Deen, T., Domack, E., Dutrieux, P., Galton-Fenzi, B., Hellmer, H., Humbert, A., Jansen, D., Jenkins, A., Lambrecht, A., Makinson, K., Niederjasper, F., Nitsche, F., Noest, O., Smedsrud, L., and Smith, W.: A consistent dataset of Antarctic ice sheet topography, cavity geometry, and global bathymetry., Earth Syst. Sci. Data, 2, 261-273, doi:10.5194/essd2-261-2010, 2010.

Timmermann, R., Wang, Q., and Hellmer, H.: Ice-shelf basal melting in a global finite-element sea-ice/ice-shelf/ocean model, Ann. Glaciol., 53, 303-314, doi:doi:10.3189/2012AoG60A156, 2012.

Van den Broeke, M. R., Bamber, J., Lenaerts, J., and Rignot, E.: Ice Sheets and Sea Level: Thinking Outside the Box, Surv. Geophys., 32, 495-505, doi:10.1007/s10712-011-9137-z, 2011.

Vizcaíno, M., Mikolajewicz, U., Jungclaus, J., and Schurgers, G.: Climate modification by future ice sheet changes and consequences for ice sheet mass balance, Clim. Dynam., 34, 301-324, doi:10.1007/s00382-009-0591-y, 2009.

Walker, R. T., Dupont, T. K., Parizek, B. R., and Alley, R. B.: Effects of basal-melting distribution on the retreat of ice-shelf grounding lines, Geophys. Res. Lett., 35, L17503, doi:10.1029/2008GL034947, 2008.

Walter, F., O’Neel, S., McNamara, D., Pfeffer, W. T., Bassis, J. N., and Fricker, H. A.: Iceberg calving during transition from grounded to floating ice: Columbia Glacier, Alaska, Geophys. Res. Lett., 37, 1-5, doi:10.1029/2010GL043201, 2010.

Walter, J. I., Box, J. E., Tulaczyk, S., Brodsky, E. E., Howat, I. M., Ahn, Y., and Brown, A.: Oceanic mechanical forcing of a marine-terminating Greenland glacier, Ann. Glaciol., 53, 181192, doi:10.3189/2012AoG60A083, 2012.

Wang, W., Li, J., and Zwally, H. J.: Dynamic inland propagation of thinning due to ice loss at the margins of the Greenland ice sheet, J. Glaciol., 58, 734-740, doi:10.3189/2012JoG11J187, 2012.

Weertman, J.: On the sliding of glaciers, J. Glaciol., 3, 33-38, 1957.

Winkelmann, R. and Levermann, A.: Linear response functions to project contributions to future sea level, Clim. Dynam., 40, 2579-2588, doi:10.1007/s00382-012-1471-4, 2013.

Winkelmann, R., Martin, M. A., Haseloff, M., Albrecht, T., Bueler, E., Khroulev, C., and Levermann, A.: The Potsdam Parallel Ice Sheet Model (PISM-PIK) Part 1: Model description, The Cryosphere, 5, 715-726, doi:10.5194/tc-5-715-2011, 2011.

Winkelmann, R., Levermann, A., Martin, M. A., and Frieler, K.: Increased future ice discharge from Antarctica owing to higher snowfall, Nature, 492, 239-242, 2012.

Yin, J., Overpeck, J., Griffies, S., Hu, A., Russell, J., and Stouffer, R. J.: Different magnitudes of projected subsurface ocean warming around Greenland and Antarctica, Nat. Clim. Change, 4, 524-528, 2011. 